\title{
Hydrogen-rich solution against myocardial injury and aquaporin expression via the PI3K/Akt signaling pathway during cardiopulmonary bypass in rats
}

\author{
DANDAN SONG ${ }^{1,2}$, XUELEI LIU ${ }^{3}$, YUGANG DIAO $^{2}$, YINGJIE SUN $^{2}$, \\ GUANGJIE GAO ${ }^{4}$, TIEZHENG ZHANG ${ }^{2}$, KEYAN CHEN $^{5}$ and LING PEI $^{1}$ \\ ${ }^{1}$ Department of Anesthesiology, The First Affiliated Hospital of China Medical University; \\ Departments of ${ }^{2}$ Anesthesiology and ${ }^{3}$ Clinical Laboratory, General Hospital of Shenyang Military Area Command, \\ Shenyang, Liaoning 110016; ${ }^{4}$ Department of Anesthesiology, The 463rd Hospital of People's Liberation Army China, \\ Shenyang, Liaoning 110012; ${ }^{5}$ Department of Laboratory Animal Science, China Medical University, \\ Shenyang, Liaoning 110122, P.R. China
}

Received September 13, 2017; Accepted January 5, 2018

DOI: $10.3892 / \mathrm{mmr} .2018 .9198$

\begin{abstract}
Myocardial ischemia, hypoxia and reperfusion injury are induced by aortic occlusion, cardiac arrest and resuscitation during cardiopulmonary bypass $(\mathrm{CPB})$, which can severely affect cardiac function. The aim of the present study was to investigate the effects of hydrogen-rich solution (HRS) and aquaporin (AQP) on cardiopulmonary bypass (CPB)-induced myocardial injury, and determine the mechanism of the phosphatidylinositol 3-kinase (PI3K)/protein kinase B (Akt) signaling pathway. Sprague Dawley rats were divided into a sham operation group, a CPB surgery group and a HRS group. A CPB model was established, and the hemodynamic parameters were determined at the termination of CPB. The myocardial tissues were observed by hematoxylin and eosin, and Masson staining. The levels of myocardial injury markers [adult cardiac troponin I (cTnI), lactate dehydrogenase $(\mathrm{LDH})$, creatine kinase $\mathrm{MB}(\mathrm{CK}-\mathrm{MB})$ and brain natriuretic peptide (BNP)], inflammatory factors [interleukin (IL)- $1 \beta$, IL-6 and tumor necrosis factor- $\alpha$ (TNF- $\alpha)$ ] and oxidative stress indicators [superoxide dismutase (SOD), malondialdehyde (MDA) and myeloperoxidase (MPO)] were determined by ELISA. Furthermore, $\mathrm{H} 9 \mathrm{C} 2$ cells were treated with HRS following hypoxia/reoxygenation. Cell viability and cell apoptosis were investigated. The expression of apoptosis regulator Bcl-2 (Bcl-2), apoptosis regulator Bax (Bax), caspase 3, AQP-1, AQP-4, phosphorylated (p)-Akt, heme oxygenase 1 (HO-1) and
\end{abstract}

Correspondence to: Dr Ling Pei, Department of Anesthesiology, The First Affiliated Hospital of China Medical University, 155 North Nanjing Street, Shenyang, Liaoning 110016, P.R. China

E-mail: lingpei49@vip.sina.com

Key words: hydrogen rich solution, cardiopulmonary bypass, phosphatidylinositol 3-kinase/AKT, myocardial injury, apoptosis, inflammation nuclear factor erythroid 2-related factor 2 (Nrf2) were investigated using western blotting and quantitative-polymerase chain reaction of tissues and cells. Following CPB, myocardial cell arrangement was disordered, myocardial injury markers (cTnI, LDH, CK-MB and BNP), inflammatory cytokines (IL-1 $\beta$, IL- 6 and TNF- $\alpha$ ) and MDA levels were significantly increased compared with the sham group; whereas the SOD levels were significantly downregulated following CPB compared with the sham group. HRS attenuated myocardial injury, reduced the expression levels of cTnI, LDH, CK-MB, BNP, IL-1 $\beta$, IL-6, TNF- $\alpha$, MDA and MPO, and increased SOD release. Levels of Bcl-2, AQP-1, AQP-4, p-Akt, HO-1 and Nrf2 were significantly increased following HRS; whereas Bax and caspase-3 expression levels were significantly reduced following CPB. HRS treatment significantly increased the viability of myocardial cells, reduced the rate of myocardial cell apoptosis and the release of MDA and LDH compared with the CPB group. A PI3K inhibitor (LY294002) was revealed to reverse the protective effect of HRS treatment. HRS was demonstrated to attenuate CPB-induced myocardial injury, suppress AQP-1 and AQP-4 expression following CPB treatment and protect myocardial cells via the PI3K/Akt signaling pathway.

\section{Introduction}

Cardiopulmonary bypass (CPB) refers to the use of artificial channels to connect the circulatory system of the body with a heart-lung machine. Venous blood is drawn from the large vein (or the right atrium) in vitro and oxygenated blood is injected into the arterial system via the blood pump. During $\mathrm{CPB}$, aortic block, cardiac arrest and resuscitation may lead to myocardial ischemia-reperfusion injury, which may result in postoperative malignant arrhythmia and low cardiac output syndrome (1). It has been previously estimated that $\sim 25 \%$ of postoperative mortality is associated with malignant cardiovascular events (2). During CPB, the main causes of myocardial injury include myocardial ischemia-reperfusion injury, systemic inflammatory response and mechanical injury (3). 
Therefore, it is important to determine the pathophysiological changes of myocardial injury during CPB in order to develop clinical myocardial protection strategies.

Ohsawa et al (4) demonstrated that hydrogen can effectively remove oxygen free radicals and attenuate cerebral ischemia and reperfusion injury. Hydrogen-rich solution (HRS) can be obtained by dissolving hydrogen under specific pressurized conditions to physiological saline. HRS is a good antioxidant, and has a high hydrogen content. It is weakly alkaline has a negative potential and contains the small molecule water (5). HRS has been demonstrated to be safe and non-toxic, and exhibits strong anti-inflammatory, anti-oxidative stress and anti-apoptotic characteristics (6). HRS exerts a protective effect on the brain, liver and intestines against ischemia-reperfusion and myocardial injury; however, the underlying therapeutic mechanism remains to be determined, thus restricting its further development and potential clinical application.

Aquaporin $(\mathrm{AQP})$ is a membrane protein responsible for the transport of water and small molecules between cells. A recent study demonstrated that $\mathrm{AQP}$ has an important role in regulating the transport in membranes and intracellular water content. At present, 13 types of AQP proteins (AQP-0-AQP-12) have been identified in mammals (7). AQP-1 is concentrated in microvascular endothelial cells and cardiomyocytes in myocardium (8). Furthermore, AQP-1 is highly expressed in cardiomyocytes and vascular endothelial cells in rabbits with chronic myocardial ischemia (9). In addition, AQP-4 protein also has an important role in myocardial edema (10). A previous study demonstrated that AQP-4 expression was downregulated following myocardial injury, thus having a protective effect (11).

The phosphatidylinositol 3'-kinase (PI3K)/protein kinase B (Akt) signaling pathway is an important signaling pathway for the regulation of cell survival, growth and proliferation, and has an important role in the regulation of the myocardial ischemia-reperfusion injury protective mechanism (12-15). Akt is in the central regulator of the PI3K/Akt pathway, and affects numerous downstream effector molecules which manage anti-ischemia-reperfusion injury (16-18). The present study aimed to investigate the effects of HRS on CPB-induced myocardial injury, AQP expression and the underlying mechanism of the PI3K/Akt signaling pathway, thus providing a novel approach for the investigation into myocardial therapeutic strategies.

\section{Materials and methods}

Animalsandcells.Atotalof 24 maleSpragueDawleyrats, weighing 350-400 g, 10-weeks-old were obtained from the Experimental Animal Center of China Medical University [Shanyang, China; production license no. SCXK (Liao)-2013-0001; application license no. SYXK (Liao)-2013-0007]. The present study was approved by the China Medical University Laboratory Animal Welfare and Ethics Committee and adhered to the guidelines of The Institutional Animal Care and Use Committee; no. 2015048R. Rat myocardial H9C2 cells were purchased from the Cell Bank of Type Culture Collection of Chinese Academy of Sciences cell repository (Shanghai, China).

Hydrogen-rich water preparation. Hydrogen-rich water (HRS) was prepared as previously reported (19): Under high pressure $(0.8 \mathrm{MPa})$, hydrogen was dissolved in saline for $24 \mathrm{~h}$ at room temperature to reach saturation level and stored in a medical vacuum bag at $4^{\circ} \mathrm{C}$ until further use.

Experimental protocols. Rats were randomly divided into 3 groups: i) Sham operation group ( $n=8)$; ii) $\mathrm{CPB}$ group $(n=8)$; and iii) $\mathrm{CPB}+\mathrm{HRS}$ group $(\mathrm{n}=8)$. In the sham group, intubation and mechanical ventilation were performed on the right femoral artery only, and the right internal jugular vein was catheterized without bypass. In the CPB group, the CPB model was established; $\mathrm{CPB}+\mathrm{HRS}$ group was treated with HRS $(6 \mathrm{ml} / \mathrm{kg})$ via the tail vein. The sham and CPB groups were injected with $0.9 \% \mathrm{NaCl}$ solution $(6 \mathrm{ml} / \mathrm{kg})$.

H9C2 cells were divided into the following experimental groups: i) CPB group; ii) HRS + CPB group (HRS group), iii) LY294002 (cat. no. PHZ1144, Invitrogen; Thermo Fisher Scientific, Inc., Waltham, MA, USA), a PI3K inhibitor + CPB (PI3K group); and iv) LY294002 + CPB + HRS (LHRS group). In the CPB group, CPB was simulated by hypoxia and reoxygenation; the HRS group was treated with $0.8 \mathrm{mM} / 1$ HRS for 3 days and a further HRS dose was administered prior to hypoxia and during reoxygenation. In the PI3K group, $40 \mu \mathrm{M} / 1$ PI3K inhibitor, LY294002 was added to H9C2 cells. In the LHRS group, both HRS and PI3K inhibitor, LY294002 $(40 \mu \mathrm{M} / \mathrm{l})$ were added.

Establishment of CPB models. Following anesthesia via an intraperitoneal injection of pentobarbital sodium, mechanical ventilation was performed using a small-animal ventilator (HX-100E, Shanghai xinman scientific equipment Co., Ltd.) with tracheal intubation by transparent method (20). ECG, deep rectal temperature and arterial pressure were monitored in real time using the Datex-Ohmeda S/5 Entropy Module (DRE, Inc., Louisville, KY, USA). CPB was performed using a venous drainage tube, a blood container, a constant flow peristaltic pump, a membrane oxygenator (extracorporeal membrane oxygenation), an arterial infusion tube, a warming blood device and a filter. The blood container was placed in front of the peristaltic pump and connected to the right internal jugular vein drainage tube. The membrane oxygenator was set up behind the pump and connected to the perfusion end of right femoral artery via the warming blood device with a pipe. There was a bypass pipe between the blood container and membrane oxygenator (ideograph is presented in Fig. 1A). When activated clotting time reached 400-500 sec, CPB began. At the beginning of CPB, the flow rate was $35 \mathrm{ml} \cdot \mathrm{kg}^{-1} \cdot \mathrm{min}^{-1}$, and this gradually increased to $100-120 \mathrm{ml} \cdot \mathrm{kg}^{-1} \mathrm{~min}^{-1}$. The blood volume was maintained at 1-2 ml. When CPB began, the respirator was terminated. Oxygen was provided by an oxygenator $\left(\mathrm{FiO}_{2}=1.0\right)$. $\alpha$-stat blood gas management was performed using a small-animal ventilator. Following $1 \mathrm{~h}$ of $\mathrm{CPB}$, mechanical ventilation was restored. The flow rate was gradually reduced and finally terminated, and each pipe was then removed from the heart. Mechanical ventilation was continuous, and rectal temperature was maintained at $36.5-37.5^{\circ} \mathrm{C}$. The remaining blood from the blood container was slowly infused, and stable circulation was maintained. Arterial blood $(0.2 \mathrm{ml})$ was collected at the following time intervals during the surgery for blood gas analysis: Prior to CPB $\left(\mathrm{T}_{0}\right)$, time of aortic occlusion $\left(\mathrm{T}_{1}\right)$, time of restoring aorta $\left(\mathrm{T}_{2}\right)$, time of CPB termination 


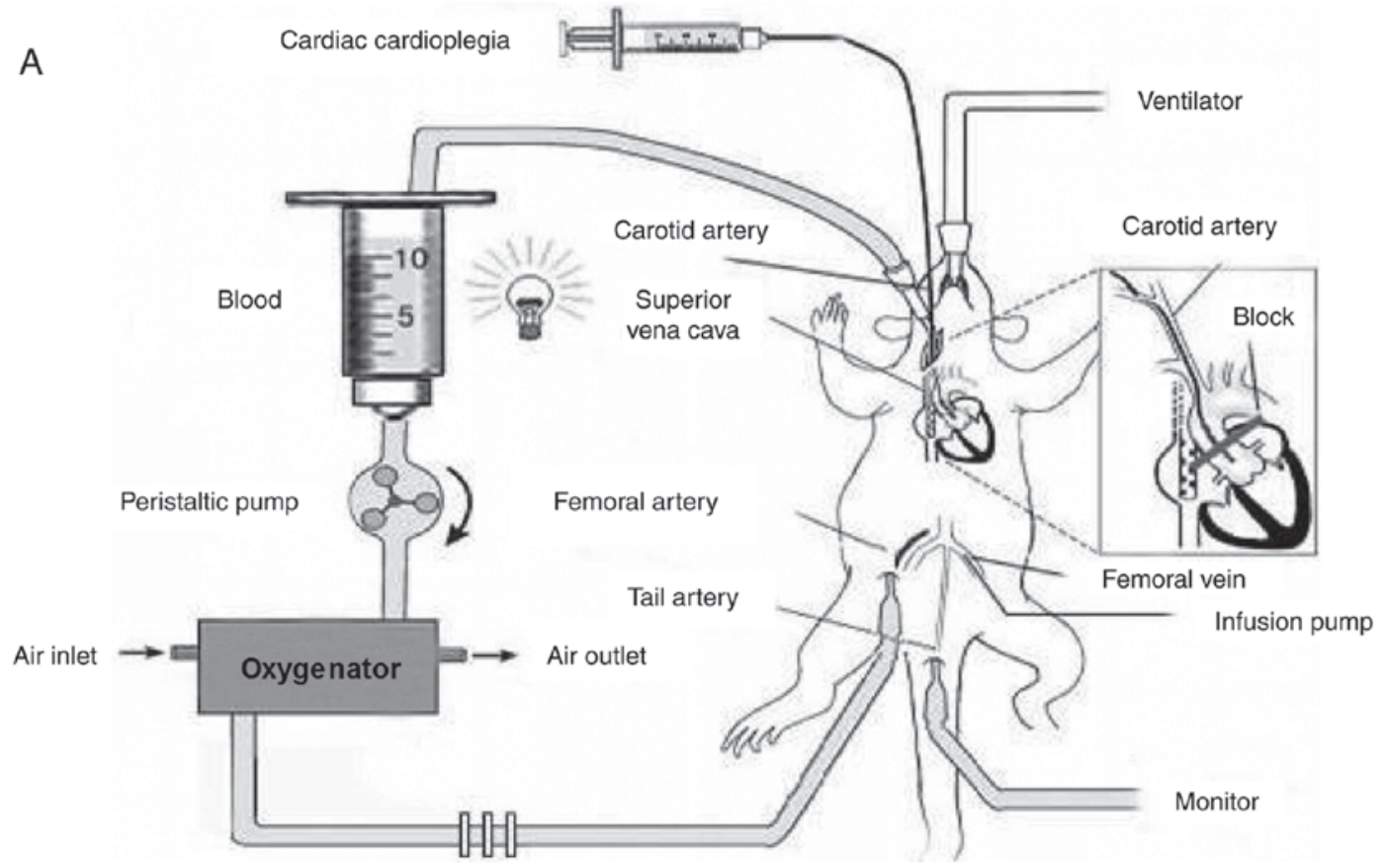

Sham

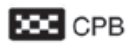

四HRS

B

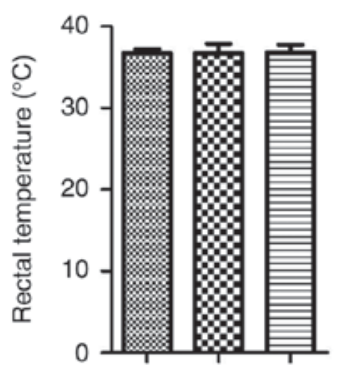

E

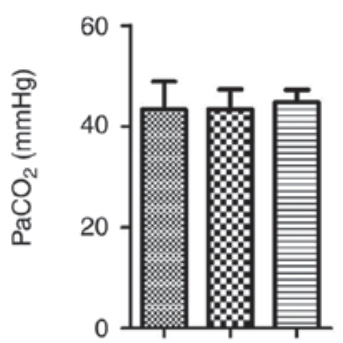

$\mathrm{H}$

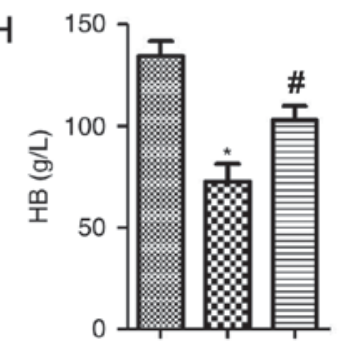

C

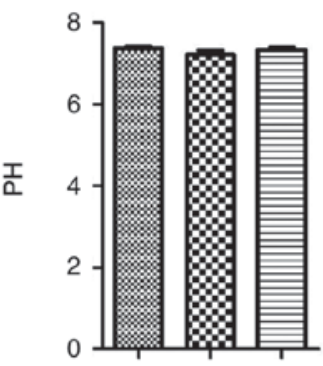

F
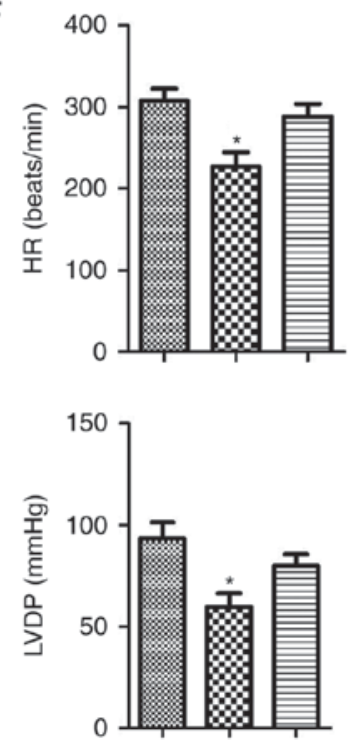

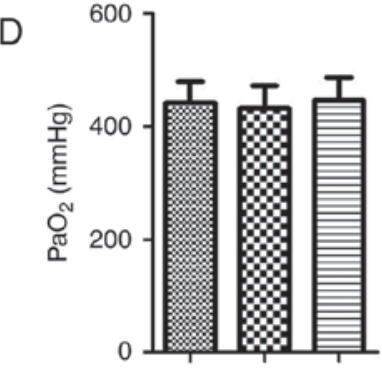

G
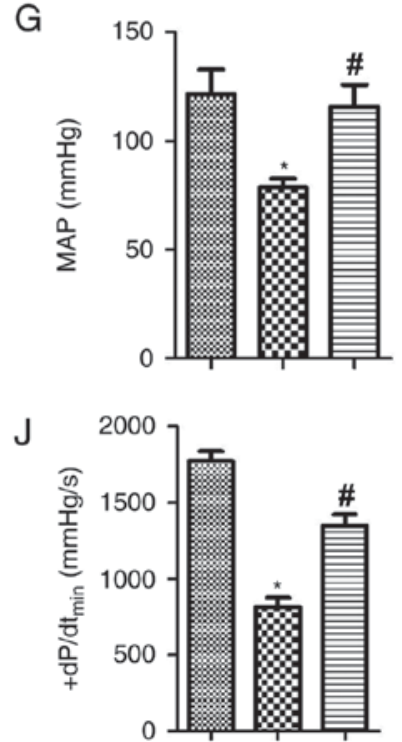

Figure 1. Establishment of the CPB rat model and the determination of hemodynamic changes. (A) Establishment of the CPB rat model. Hemodynamic changes exhibited by the sham, CPB and HRS groups were categorized as (B) rectal temperature, (C) pH, (D) PaO $\mathrm{P}_{2}$, (E) PaCO,$(\mathrm{F}) \mathrm{HR}$, (G) MAP, (H) HB, (I) LVDP

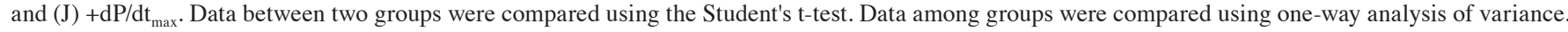
${ }^{*} \mathrm{P}<0.05$ vs. sham group; ${ }^{\text {P }}<0.05$ vs. CPB group. $\mathrm{CPB}$, cardiopulmonary bypass; HRS, hydrogen rich solution; $+\mathrm{dP}^{\mathrm{dt}} \mathrm{max}_{\text {max }}$, the highest rate of change of pressure development; $\mathrm{PaO}_{2}$, oxygen partial pressure; $\mathrm{PaCO}_{2}$, carbon dioxide partial pressure; HR, heart rate; MAP, mean arterial pressure; HB, hemoglobin; LVDP, left ventricular diastolic pressure. 
$\left(\mathrm{T}_{3}\right)$ and $2 \mathrm{~h}$ following CPB $\left(\mathrm{T}_{4}\right)$. Blood loss during blood gas analysis was supplemented with $6 \%$ hydroxyethyl starch.

Hemodynamic changes. All rats had awakened 60-90 min following anesthesia. Hemodynamics were detected using the Datex-Ohmeda S/5 Entropy Module (DRE, Inc.). Rectal temperature, $\mathrm{pH}$, arterial $\mathrm{CO}_{2}$ partial pressure $\left(\mathrm{PaCO}_{2}\right)$, oxygen partial pressure $\left(\mathrm{PaO}_{2}\right)$, heart rate $(\mathrm{HR})$, mean arterial pressure (MAP), left ventricular diastolic pressure (LVDP), the highest rate of change of pressure development $\left(+\mathrm{dP} / \mathrm{dt}_{\max }\right)$ and hemoglobin $(\mathrm{Hb})$ were recorded.

Specimen collection and processing. Arterial and venous blood samples were respectively collected at CPB for $6 \mathrm{~h}$ following the sacrifice of rats via administration of an overdose of anesthesia of sodium pentobarbital. Venous blood was sterilely obtained, anticoagulated with heparin and then centrifuged at $1,000 \mathrm{x}$ g for $5 \mathrm{~min}$ at $4^{\circ} \mathrm{C}$. Blood plasma was isolated, packed separately, and stored at $-80^{\circ} \mathrm{C}$ for further use. Following this, the myocardial tissue was isolated from the rat and one part was fixed in $4 \%$ paraformaldehyde and the other part was stored at $-80^{\circ} \mathrm{C}$ for subsequent western blotting and polymerase chain reaction (PCR) analysis. The sera were separated by centrifugation at $1,000 \mathrm{x}$ g for $10 \mathrm{~min}$ at $4^{\circ} \mathrm{C}$, and then stored at $-80^{\circ} \mathrm{C}$.

Determination of myocardial water content. The moisture on the surface of left ventricle $(\sim 100 \mathrm{mg})$ was blotted, hydrated at $100^{\circ} \mathrm{C}$ for $24 \mathrm{~h}$, and then baked for weighing. According to the Ellis formula: Myocardial water content=(wet weight-dry weight)/wet weight $\times 100 \%$.

Establishment of hypoxia-reoxygenation model. The hypoxic solution was used to simulate the CPB process in $\mathrm{H} 9 \mathrm{C} 2$ myocardial cells. The hypoxic solution ( $\mathrm{pH}$ 6.5) consisted of: $\mathrm{NaCl}(137 \mathrm{mM}), \mathrm{KCl}$ (12 mM), $\mathrm{MgCl}_{2}$ (0.49 mM), $\mathrm{CaCl}_{2}-2 \mathrm{H}_{2} \mathrm{O}$ (0.9 mM), 4-(2-hydroxyethyl)-1-piperazineethanesulfonic acid (4 mM), deoxyglucose $(10 \mathrm{mM})$, sodium sulfite $(0.75 \mathrm{mM})$ and sodium lactate $(20 \mathrm{mM})$. During hypoxia, the cells were placed in $95 \% \mathrm{~N}_{2}$ and $5 \% \mathrm{CO}_{2}$ for $2 \mathrm{~h}$ at $37^{\circ} \mathrm{C}$. During reoxygenation, the cells were incubated in normal culture medium for $4 \mathrm{~h}$ at $37^{\circ} \mathrm{C}$.

Myocardial morphology as observed by hematoxylin \& eosin $(H \& E)$ staining. Myocardium was washed with $0.9 \%$ physiological saline, immersed in $10 \%$ neutral formaldehyde for $48 \mathrm{~h}$ at room temperature, dehydrated, embedded in wax and then sliced into $5 \mathrm{~mm}$-thick sections using a ultramicrotome (LKB-8800, GE Healthcaew, Chicago, IL, USA). Following H\&E staining (with $10 \%$ hematoxylin for $10 \mathrm{~min}$, differentiated with $1 \%$ hydrochloric acid and ethanol for 3-5 sec, stained with $0.5 \%$ eosin for $1 \mathrm{~min}$ ) at room temperature. Each tissue was observed under 4-6 randomly selected visual fields using a light microscope (magnification, x200, Lecia DM5500B; Lecia Microsystems GmbH, Wetzlar, Germany).

Masson staining. Paraffin sections (5 $\mu \mathrm{m})$ were dewaxed using distilled water and then stained using 5\% Regaud dye hematoxylin staining with Masson stain for 5-10 min (All staining treatments were carried out at room temperature). Sections were then washed and stained using 0.7\% Ponceau Fuchsin acid solution for 5-10 min; using 2\% acetic acid aqueous solution soak for a moment, samples were differentiated in $1 \%$ phosphomolybdic acid aqueous solution for 3-5 min. The sections were directly stained with $2 \%$ aniline blue for $5 \mathrm{~min}$. Following dehydration with a ethanol series, cleaning with xylene and mounting with neutral resins, digital images were captured using a light microscope (maginification, x200, Lecia DM5500B; Lecia Microsystems GmbH).

ELISA detection. The expression of the following markers of myocardial injury were determined in myocardial tissue using ELISA kits against the following proteins in accordance with the manufacturer's protocol: Cardiac troponin I (cTnI; cat. no. SEA478Ra; Cloud-Clone Corp., Wuhan, China), lactate dehydrogenase (LDH; cat. no. SEB864Ra; Us Cloud-Clone Corp.), creatine kinase MB (CK-MB; cat. no. SEA479Ra; Cloud-Clone Corp.), brain natriuretic peptide (BNP; cat. no. CEA541Ra; Cloud-Clone Corp.); inflammatory cytokines: interleukin (IL)-1 $\beta$ (cat. no. SEA563Ra; Cloud-Clone Corp.), IL-6 (cat. no. SEA079Ra; Cloud-Clone Corp.), tumor necrosis factor $\alpha$ (TNF- $\alpha$; cat. no. SEA133Ra; Cloud-Clone Corp.); oxidative stress: superoxide dismutase (SOD; cat. no. SES134Ra; Cloud-Clone Corp.), malondialdehyde (MDA; cat. no. CEA597Ge; Cloud-Clone Corp.) and myeloperoxidase (MPO; cat. no. SEA601Ra; Cloud-Clone Corp.). Diluted standard substance (50 $\mu 1$, of the aforementioned ELISA kits), detected samples $(50 \mu \mathrm{l})$ and biotin-labeled antibody $(50 \mu \mathrm{l})$ were added to 96 -well plates and incubated at $37^{\circ} \mathrm{C}$ for $1 \mathrm{~h}$, washed with washing buffer from the aforementioned ELISA kits and then shaken for $30 \mathrm{sec}$. This process was repeated three times. Streptavidin-horseradish peroxidase (HRP) was then added to each well and incubated at $37^{\circ} \mathrm{C}$ for $30 \mathrm{~min}$, washed and shaken for $30 \mathrm{sec}$. This process was repeated three times. Substrates A and B (each $50 \mu \mathrm{l}$ ) were added to each well, shaken and incubated at $37^{\circ} \mathrm{C}$ for $10 \mathrm{~min}$ in the dark. The microplate was then removed and the reaction was terminated. Optical density (OD) values were then determined at $450 \mathrm{~nm}$ in each well.

Western blot assay. The samples underwent ultrasonic focalization decomposition and centrifuged in a pre-chilled tissue lysate at $16,000 \mathrm{x}$ g for $30 \mathrm{~min}$ at $4^{\circ} \mathrm{C}$. Subsequently, the supernatant was collected and protein quantification was performed by bicinchoninic acid assay (cat. no. 23230, Pierce; Thermo Fisher Scientific, Inc.), and equal amounts of protein lysate $(40 \mu \mathrm{g})$ were separated by $12 \%$ SDS-PAGE. The protein was semi-dried prior to polyvinylidene difluoride membrane transfer. Following this, membranes were blocked for $2 \mathrm{~h}$ at room temperature in TBS with 20\% Tween-20 (TBST) buffer and then incubated overnight at $4{ }^{\circ} \mathrm{C}$ with antibodies against: Bcl-2 (1:500; cat. no. ab59348; Abcam, Cambridge, MA, USA), Bax (1:1,000; cat. no. ab32503; Abcam), caspase-3 (1:500; cat. no. ab13847; Abcam), AQP-1 (1:1,000; cat. no. ab15080; Abcam), AQP-4 (diluted to $1 \mu \mathrm{g} / \mathrm{ml}$, cat. no. ab46182; Abcam), PI3K (1:1,000; cat. no. ab191606; Abcam), P-PI3K (1:500; cat. no. ab138364; Abcam), Akt (1:10,000; cat. no. ab179463; Abcam), p-Akt (1:500; cat. no. ab131443; Abcam) heme oxygenase-1 (HO-1; diluted to $4 \mu \mathrm{g} / \mathrm{ml}$, cat. no. ab13248; Abcam) and GAPDH (1:2,500; cat. no. ab9485; Abcam). 
Following this, membranes were washed with TBST buffer three times and then incubated with Goat anti-Mouse HRP IgG H\&L (1:2,000; cat. no. ab6789, Abcam) for HO-1 and Goat anti-Rabbit HRP IgG H\&L (1:2,000; cat. no. ab205718, Abcam) to for others for $1 \mathrm{~h}$ at $4^{\circ} \mathrm{C}$. Following four washes with tris-buffered saline with $0.1 \%$ Tween-20, cells were developed using a Novex ${ }^{\mathrm{TM}}$ ECL Chemiluminescent Substrate Reagent kit (cat. no. WP20005 Invitrogen; Thermo Fisher Scientific, Inc.) and gel imaging system. Gray value was determined using Quantity One software (ImageJ, v1.8.0, National Institutes of Health).

Cell transfection. H9C2 cells were transfected with a plasmid containing JAK2 small interfering (si)RNA (10 $\mu \mathrm{M}$, sc-270385, Santa Cruz Biotechnology, Inc., Dallas, TX, USA) and then seeded into 6-well culture plates at a density of $2 \times 10^{5}$ cells/well with high-glucose Dulbecco's modified Eagle's medium (Gibco; Thermo Fisher Scientific, Inc.) in a $5 \% \mathrm{CO}_{2}$ incubator for $24 \mathrm{~h}$ at $37^{\circ} \mathrm{C}$. A total of $100 \mu \mathrm{l}$ transfection medium mixed with 20-80 pM JAK2 siRNA (solution A) and then mixed with 2-8 $\mu$ l siRNA transfection reagent of Lipofectamine ${ }^{\circledR} 2000$ (Thermo Fisher Scientific, Inc.). Following mixing, solutions $\mathrm{A}$ and $\mathrm{B}$ solution were incubated for $45 \mathrm{~min}$ at room temperature, cells were rinsed with $2 \mathrm{ml}$ siRNA transfection medium, and then $0.8 \mathrm{ml}$ siRNA transfection medium was added to the mixture of solutions $\mathrm{A}$ and $\mathrm{B}$, and cells were incubated in a $\mathrm{CO}_{2}$ incubator for $7 \mathrm{~h}$ at $37^{\circ} \mathrm{C}$. Following a $24 \mathrm{~h}$ incubation at $37^{\circ} \mathrm{C}$, cells were used for further experiments. In the HRS group, cells were treated with HRS at hypoxia for $2 \mathrm{~h}$ at room temperature and then given reoxygenation for $4 \mathrm{~h}$ at room temperature.

MTT colorimetry. The cells in logarithmic growth phase were inoculated into 96-well culture plates at a density of $2,000-5,000$ cells/well and $100 \mu \mathrm{l}$ cells/well. A total of $20 \mu \mathrm{l}$ of MTT solution $(5 \mathrm{mg} / \mathrm{ml})$ was added to each well, and cells were cultured for a further $4 \mathrm{~h}$ at $37^{\circ} \mathrm{C}$. Following this, the supernatant was removed, cells were shaken for $10 \mathrm{~min}$ and then the crystals were fully dissolved using dimethyl sulfoxide (150 $\mu \mathrm{l})$. Optical density (OD) at $450 \mathrm{~nm}$ was determined via ELISA assay, and the cell survival and inhibition rates were investigated using the respective formulae: Cell survival rate $=(\mathrm{OD}$ value of the intervention group/OD value of the normal control group) $x 100$; inhibition rate $=1-O D$ value of the intervention group/OD value of the control group.

Annexin VIPI staining. The Annexin V-PI (BD 556547, USA) method was used to detect the apoptosis rate of $\mathrm{H} 9 \mathrm{C} 2$ cells via flow cytometry. Cells were harvested with $0.05 \%$ trypsin, washed three times with cold PBS $\left(4^{\circ} \mathrm{C}\right)$, and collected by centrifugation at $110 \mathrm{x}$ g for $5 \mathrm{~min}$ at $4^{\circ} \mathrm{C}$. Following this, cells were resuspended in $200 \mu \mathrm{l}$ binding buffer and incubated with Annexin V $(10 \mu \mathrm{g} / \mathrm{ml})$ and PI $(10 \mu \mathrm{g} / \mathrm{ml})$ in the dark for $15 \mathrm{~min}$ at room temperature. Then cells were detected with a flow cytometer (BD, USA).

Terminal deoxynucleotidyl-transferase-mediated dUTP nick end labeling (TUNEL) assay. Apoptotic rates of heart tissues were investigated using the In situ cell death detection kit-POD (Sigma-Aldrich; Merck KGaA; cat. no. 11684817910) according to the manufacturer's instructions. Heart tissues were fixed in $10 \%$ formaldehyde for $24 \mathrm{~h}$ at room temperature, and then dehydrated, embedded, sliced and incubated with $0.9 \% \mathrm{NaCl}$ for $5 \mathrm{~min}$ at room temperature. Samples were then rinsed twice with $\mathrm{PBS}$, mixed with biotinylated nucleotides and terminal deoxynucleotidyl transferase, covered with plastic coverslips and then incubated at $37^{\circ} \mathrm{C}$ for $60 \mathrm{~min}$. A total of $50 \mu \mathrm{l}$ of TUNEL reaction mixture was added to the sections and then incubated for $60 \mathrm{~min}$ at $37^{\circ} \mathrm{C}$ in a humidified atmosphere in the dark. The slides were rinsed three times in PBS for 5 min at room temperature. Samples were then mounted with PBS and then analyzed using fluorescence microscope (magnification, x200).

4',6-diamidino-2-phenylindole (DAPI) staining. Heart tissues were fixed in $10 \%$ formaldehyde for $24 \mathrm{~h}$ at room temperature, and then dehydrated, embedded and sliced into $5 \mu \mathrm{m}$ sections. DAPI dye solution (1 mg/ml, cat. no. C0060; Beijing Solarbio Science \& Technology Co., Ltd., Beijing, China) was applied to samples and stained for $10 \mathrm{~min}$ at room temperature. The dye solution was rinsed off and filter paper was used to remove excess water; a drop of fluorescent sealing solution (Anti-Fluorescence Attenuation Envelope Containing DAPI, cat. no. S2110, Beijing Solarbio Science \& Technology Co. Ltd.) was added and sample were analyzed using a fluorescence microscope and an excitation wavelength of $360 \mathrm{~nm}$ (magnification, x200).

Reverse transcription-quantitative PCR (RT-qPCR). Primers were designed according to the sequences of Bax, Bcl-2 and caspase 3 reported in Genbank (National Center for Biotechnology, Bethesda, MD, USA), and were synthesized by Sangon Biotech Co., Ltd. (Shanghai, China). Total RNA was isolated from myocardial samples or H9C2 cells using TRIzol reagent (Invitrogen; Thermo Fisher Scientific, Inc.) and reverse transcribed into cDNA using 5X PrimeScript RT Master Mix $2 \mu \mathrm{l}$ (RR036A, Takara Biotechnology Co., Ltd., Dalian, China) and $8 \mu \mathrm{l}$ total RNA. The RT reaction was conducted at: $37^{\circ} \mathrm{C}$ for $15 \mathrm{~min}$ and then at $85^{\circ} \mathrm{C}$ for $5 \mathrm{sec}$. cDNA was then stored at $4^{\circ} \mathrm{C}$ until use. A SYBR ${ }^{\circledR}$ Premix Ex Taq ${ }^{\mathrm{TM}}$ kit (RR820A; Takara Biotechnology Co., Ltd.) was used for detection. The following thermocycling conditions were used for RT-qPCR: Initial denaturation at $95^{\circ} \mathrm{C}$ for $30 \mathrm{sec} ; 40$ cycles of $95^{\circ} \mathrm{C}$ for $5 \mathrm{sec}$ and $60^{\circ} \mathrm{C}$ for $30 \mathrm{sec}$. Relative gene expression data were analyzed using the $2^{-\Delta \Delta C q}$ method (21). The primers used for qPCR were as follows: Bax forward, 5'-GTGGATACA GACTCCCCC-3' and reverse, 5'-AGCGGCTGTTTGTCT GGA-3'; Bcl-2 forward, 5'-TGATAACCGGGAGATCGT-3' and reverse, 5'-TCTCTGAAGACGCTGCTC-3'; caspase-3 forward, 5'-TGAATGGAAACAACCAGT-3' and reverse, 5'-TCAAGCACCTGACCCTTA-3'; AQP-1 forward, 5'-CTG AGGAAAGGCAGCTAGA-3' and reverse, 5'-TCTGGACTC AAGCTTTCTGG-3'; AQP-4 forward, 5'-TTAAGATCAGGG TGCTCC-3' and reverse, 5'-AATGTGCCCCACTATTCC-3'; and GAPDH forward, 5'-AACTTTGGCATTGTGGAA-3' and reverse, 5'-CACATTGGGGGTAGGAAC-3'.

Statistical analysis. Data were expressed as the mean \pm standard deviation and analyzed using SPSS version 13.0 software (SPSS, Inc., Chicago, IL, USA). Mean values were compared 
among groups using one-way analysis of variance followed by a Tukey's post-hoc test. Bivariate analysis was determined using linear regression and Pearson's correlation analysis. $\mathrm{P}<0.05$ was considered to indicate a statistically significant difference.

\section{Results}

Changes in rat hemodynamics. All rats were awake 60-90 min following anesthesia. The hemodynamics were detected by the Datex-Ohmeda S/5 Entropy Module (DRE, Inc.). During $\mathrm{CPB}$, levels of rectal temperature (Fig. 1B), pH (Fig. 1C), $\mathrm{PaCO}_{2}$ (Fig. 1D) and were stable, and $\mathrm{PaO}_{2}$ (Fig. 1E) did not exhibit a significant difference compared with the sham group. Furthermore, levels of HR (Fig. 1F), MAP (Fig. 1G),

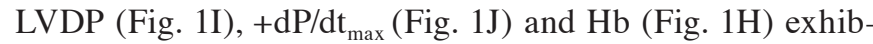
ited a significant decrease compared with the sham group; however, following treatment with HRS, these parameters were significantly increased when compared with the sham group $(\mathrm{P}<0.05)$.

$H R S$ protects against myocardial injury in CBP rats. To investigate the effects of HRS treatment during $\mathrm{CPB}$, myocardial cells were stained with $H \& E$. H\&E staining revealed that myocardial cells were arranged in order in the sham group, with clear boundaries and intact nuclei (Fig. 2A). Myocardial cells in the CPB group were arranged disorderly, with unclear boundaries, myofiber ruptures and nuclei degradation (Fig. 2A). In the HRS group, HRS ameliorated myocardial injury. Masson trichrome staining of myocardial cells revealed myocardial fibrosis and marked damage in the CPB group, and myocardial fiber damage was attenuated in the HRS group (Fig. 2B). The levels of LDH, CK-MB and cTnI were significantly increased in $\mathrm{CPB}$ group compared with the sham group $(\mathrm{P}<0.05$; Fig. $2 \mathrm{C}-\mathrm{E})$, HRS treatment reversed the $\mathrm{LDH}$, CK-MB and cTnI back toward normal levels. There was no significant difference in BNP levels (Fig. 2F). These findings suggest that HRS protects myocardial cells from CPB.

HRS attenuates mitochondrial oxidative stress and secretion of inflammatory factors in CPB rats. The results of the ELISA analyses demonstrated that levels of MDA and MPO were significantly enhanced in the CPB group compared with the sham group $(\mathrm{P}<0.05$; Fig. $3 \mathrm{~A}$ and $\mathrm{B})$; whereas the level of SOD was significantly reduced in the CPB group compared with the sham group (Fig. 3C). Following HRS treatment, the levels of MDA and MPO were significantly reduced when compared with the $\mathrm{CPB}$ group $(\mathrm{P}<0.05$; Fig. $3 \mathrm{~A}$ and $\mathrm{B})$. The expression levels of inflammatory factors (IL-1 $\beta$, IL-6 and TNF- $\alpha$ ) were significantly increased in the CPB group compared with the sham group $(\mathrm{P}<0.05$; Fig. 3D-F); whereas following HRS treatment, the levels of IL- $1 \beta$, IL- 6 and TNF- $\alpha$ were significantly reduced (Fig. 3D-F). Therefore, the current findings suggest that treatment with HRS attenuates mitochondrial oxidative stress and secretion of inflammatory factors in the CPB rat.

HRS protects the heart from CPB-induced apoptosis. To analyze the effects of HRS on apoptosis levels in the CPB group, TUNEL assays were performed, and the results demonstrated that the number of TUNEL-positive cells was significantly greater in the CPB group compared with the sham group, and the number of TUNEL-positive cells significantly decreased following HRS intervention compared with the CPB group $(\mathrm{P}<0.05$; Fig. 4A and B). Furthermore, the expression levels of apoptosis-associated proteins were investigated. The levels of Bax and caspase- 3 in heart tissue were significantly higher following $\mathrm{CPB}(\mathrm{P}<0.05$; Fig. 4C-G); whereas Bcl-2 expression was significantly suppressed in the $\mathrm{CPB}$ group compared with the sham group $(\mathrm{P}<0.05$; Fig. $4 \mathrm{C}, \mathrm{H}$ and $\mathrm{I})$. Following HRS treatment, Bax and caspase-3 expression levels were significantly reduced $(\mathrm{P}<0.05$; Fig. $4 \mathrm{C}-\mathrm{G})$, and the expression level of Bcl-2 was increased following HRS treatment $(\mathrm{P}<0.05$; Fig. $4 \mathrm{C}, \mathrm{H}$ and I). Therefore, these findings suggest that $\mathrm{CPB}$ induces apoptosis in heart tissue; however, HRS treatment attenuates this effect.

HRS inhibits AQP protein expression following CPB in rats. In order to verify the mRNA and protein expression levels of AQP-1 and AQP-4 following CPB, western blot assays and RT-qPCR analyses were performed. Results of western blot assays were consistent with those obtained by the RT-qPCR analyses. Compared with sham group, AQP-1 and AQP-4 mRNA and protein expression levels significantly increased following $\mathrm{CPB}$ treatment compared with the sham group ( $\mathrm{P}<0.05$; Fig. 5). Compared with the CPB group, AQP-1 and AQP-4 mRNA and protein expression levels were suppressed following treatment with HRS $(\mathrm{P}<0.05$; Fig. 5). Thus, the results suggest that administration of HRS can inhibit myocardial edema otherwise induced by CPB.

HRS inhibits apoptosis via the PI3K/Akt signaling pathway following $C P B$ in rats. To investigate whether the PI3K/Akt signaling pathway regulates apoptosis, the levels of several important factors in the signaling pathway were determined. The results revealed that $\mathrm{PI} 3 \mathrm{~K}$, p-Akt and HO-1 levels were increased in the CPB group $(\mathrm{P}<0.05)$; however, treatment with HRS significantly attenuated these effects (Fig. 6A and B). The results suggest that HRS protects against CPB-induced cell apoptosis, and this may be regulated via the PI3K/Akt signaling pathway.

HRS enhances viability of myocardial cells. The cell viability in each group was investigated via MTT assays following reoxygenation. The results of the MTT assays revealed that HRS treatment increased the viability of myocardial cells following HRS treatment $(\mathrm{P}<0.05$; Fig. 7A). Therefore, HRS was demonstrated to enhance the viability of myocardial cells.

HRS protects myocardial cells from apoptosis in vitro. The Annexin V-PI method was used to investigate the apoptosis rate of myocardial cells. As revealed in Fig. 7B and C, HRS treatment significantly suppressed the apoptotic rate of myocardial cells following HRS treatment $(\mathrm{P}<0.05)$. Furthermore, western blot analyses revealed that Bax and caspase-3 expression levels were suppressed (Fig. 7D-F), and the expression of Bcl-2 protein was enhanced in the HRS group (Fig. 7D and G). These results suggest that HRS can protect myocardial cells from undergoing apoptosis.

HRS inhibits myocardial cell apoptosis via the PI3K/Akt signaling pathway. The mechanism underlying the anti-apoptotic 
A

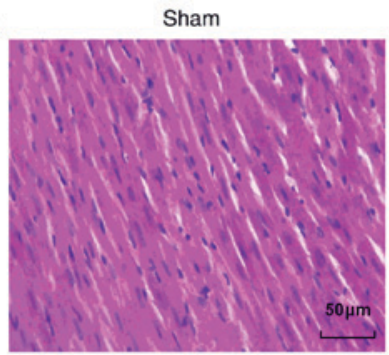

B

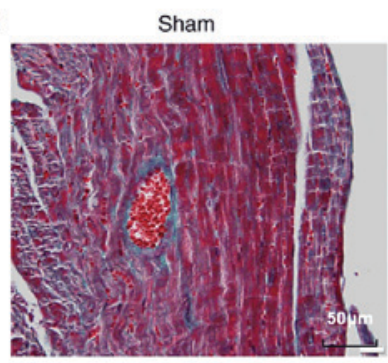

CPB

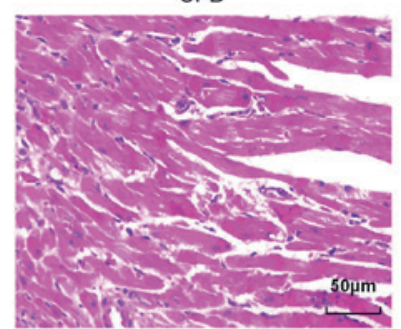

CPB

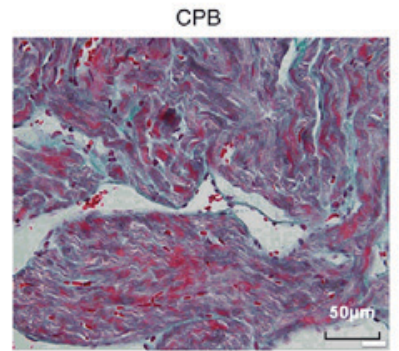

HRS

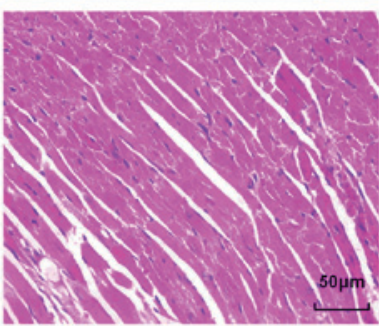

HRS
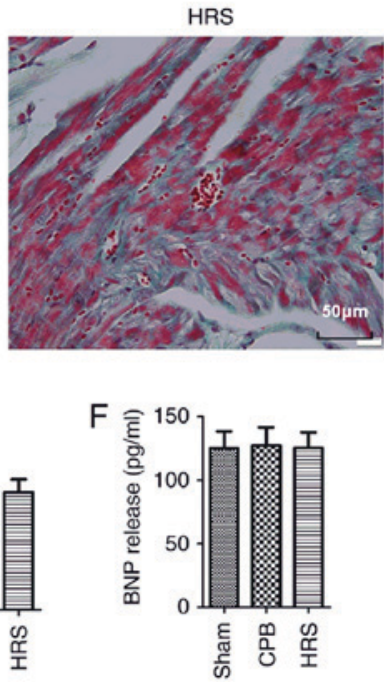

Figure 2. HRS attenuated myocardial injury in CPB rats. Following HRS treatment, rat myocardial tissue was collected. (A) Hematoxylin and eosin staining (Scale bar $=50 \mu \mathrm{m}$ ) and (B) Masson staining (Scale bar=50 $\mu \mathrm{m}$ ) were used to observe the pathological changes. ELISA was performed to determine the expression levels of (C) LDH, (D) CK-MB, (E) cTnI and (F) BNP myocardial injury markers. Data between two groups were compared using the Student's t-test. Data among groups were compared using one-way analysis of variance. ${ }^{*} \mathrm{P}<0.05$ vs. sham group; ${ }^{\#} \mathrm{P}<0.05$ vs. CPB group. CPB, cardiopulmonary bypass; $\mathrm{HRS}$, hydrogen rich solution; $\mathrm{LDH}$, lactate dehydrogenase; CK-MB, creatine kinase MB; cTnI, adult cardiac troponin I; BNP, brain natriuretic peptide.

A
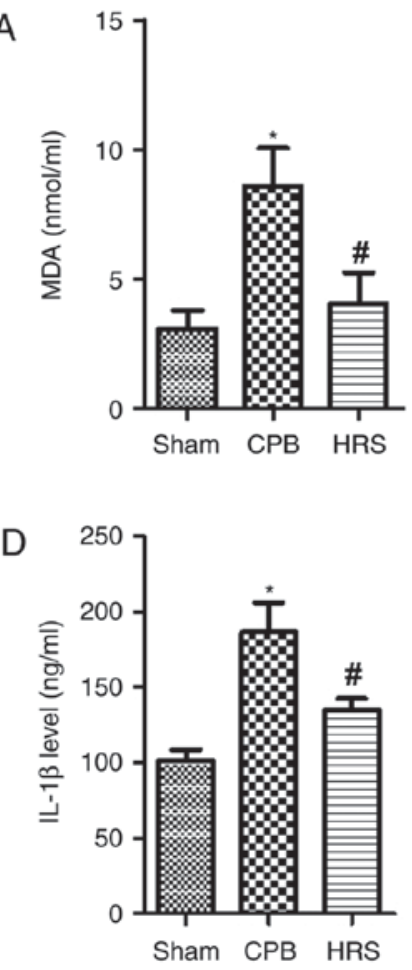

B

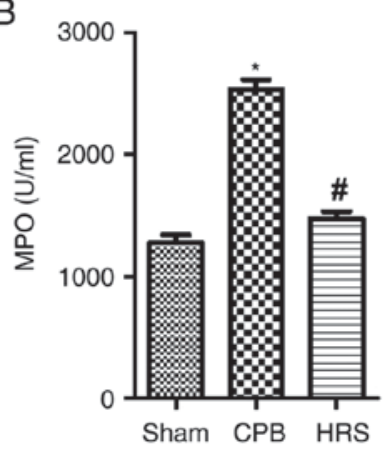

$\mathrm{E}$

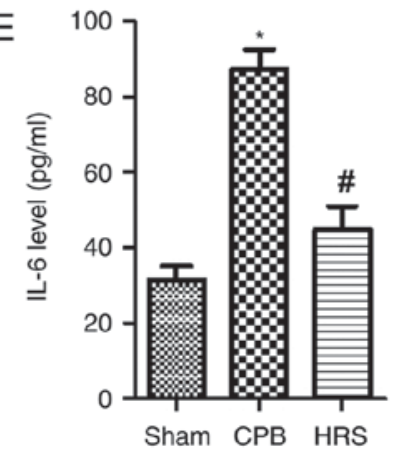

C

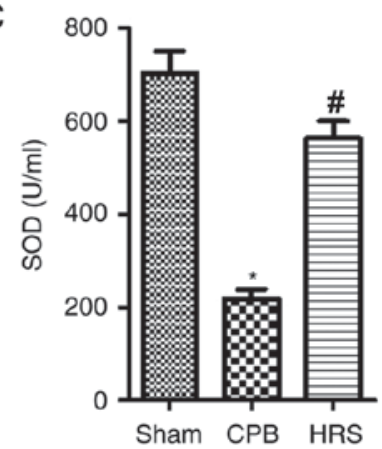

$\mathrm{F}$

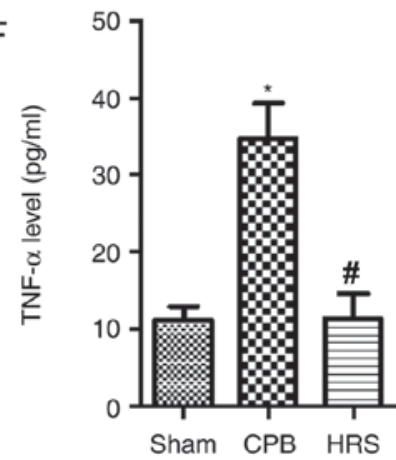

Figure 3. HRS attenuated mitochondrial oxidative stress and secretion of inflammatory factors in CPB rats. Following HRS treatment, rats serum was collected, ELISA was performed to determine the expression levels of (A) MDA, (B) MPO, (C) SOD, (D) IL-1 1 , (E) IL-6 and (F) TNF- $\alpha$. Data among groups were compared using one-way analysis of variance. ${ }^{*} \mathrm{P}<0.05$ vs. sham group; ${ }^{*} \mathrm{P}<0.05$ vs. $\mathrm{CPB}$ group. $\mathrm{CPB}$, cardiopulmonary bypass; HRS, hydrogen rich solution; MDA, malondialdehyde; MPO, myeloperoxidase; SOD, superoxide dismutase; IL, interleukin; TNF- $\alpha$, tumor necrosis factor- $\alpha$. 
A
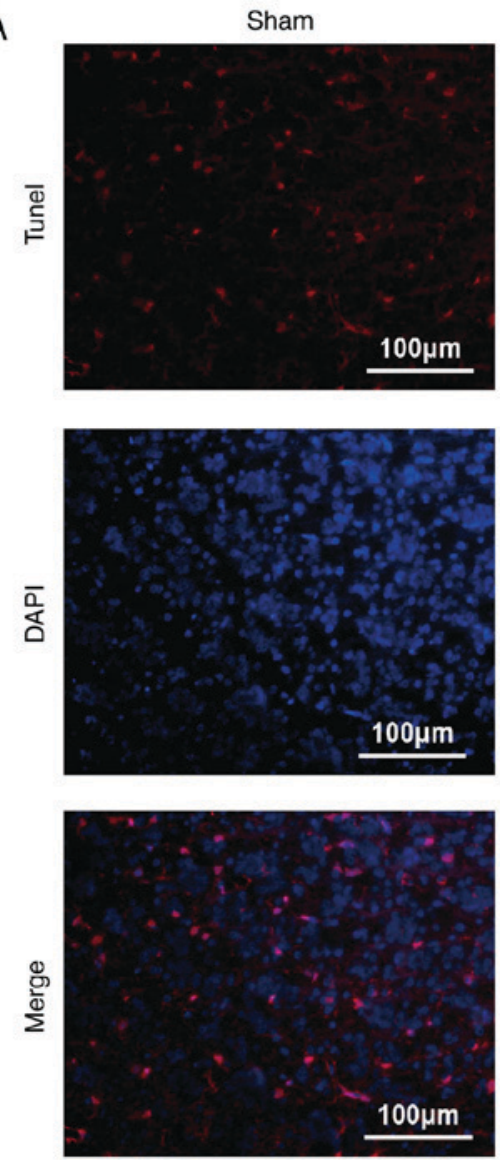

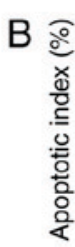

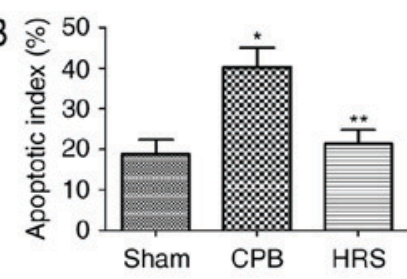

CPB
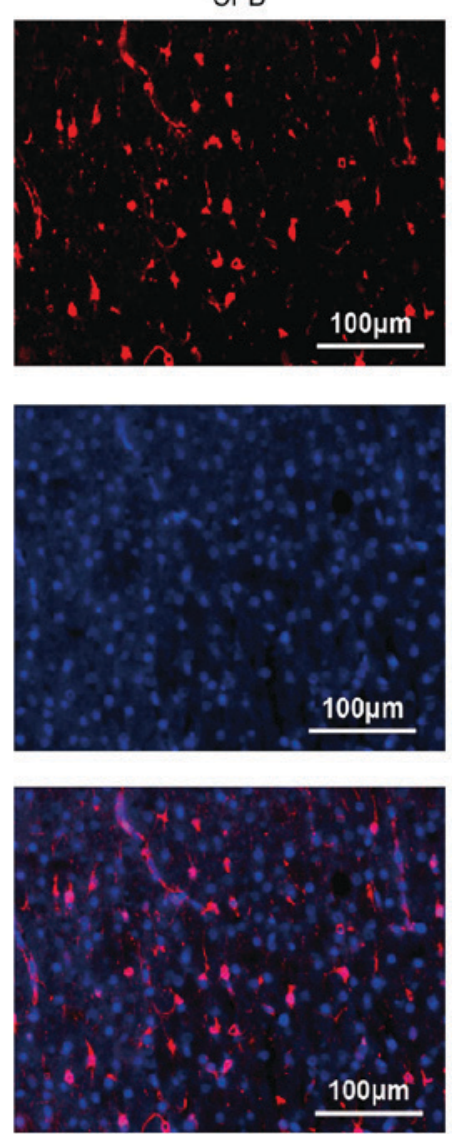

C
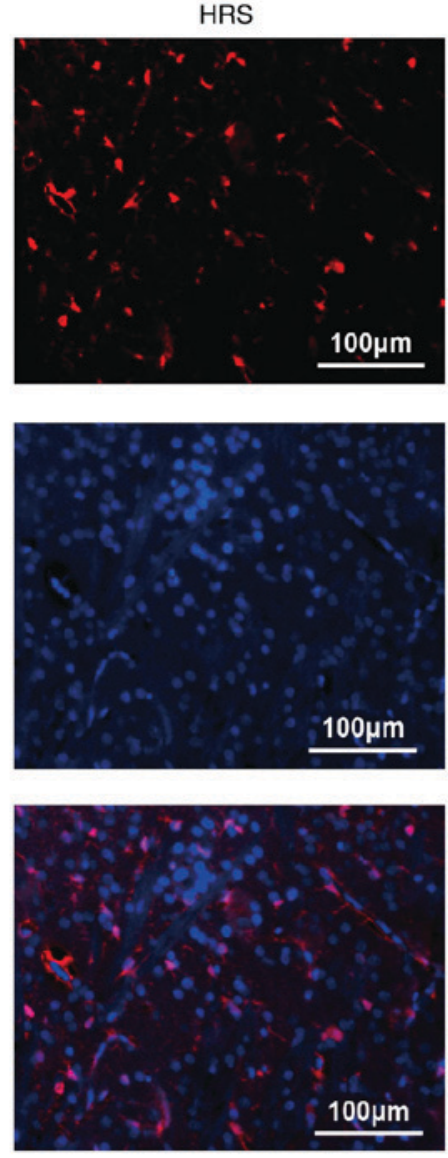

Sham CPB HRS

Bax

Bcl2

Caspase-3

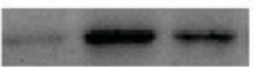

GAPDH
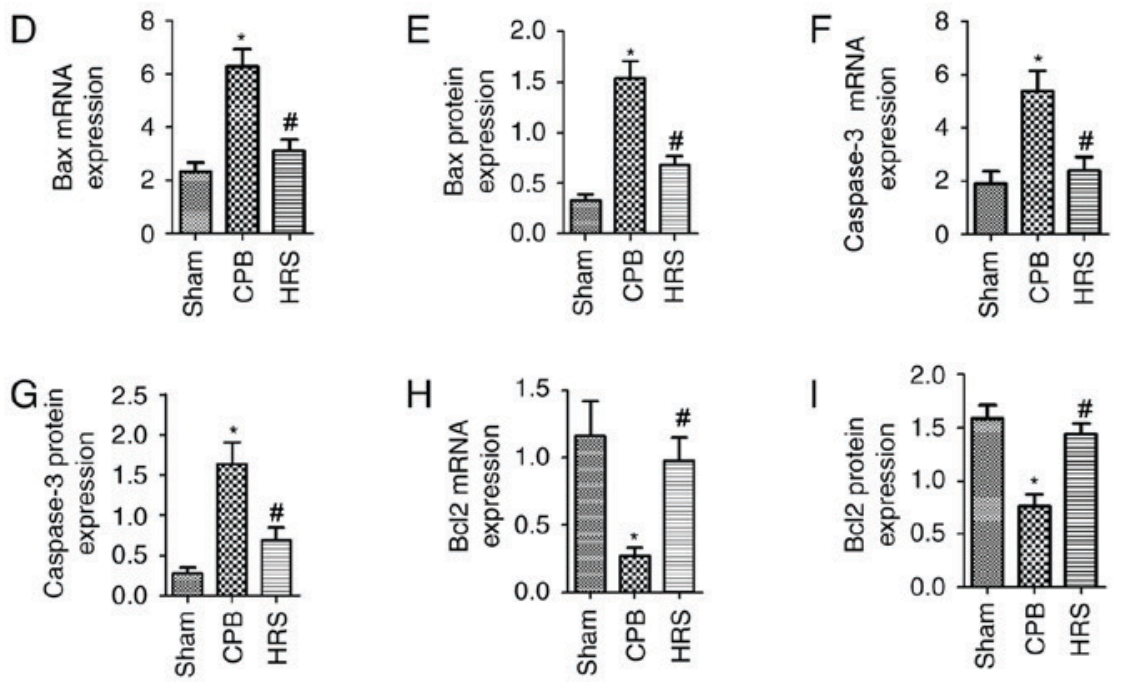

Figure 4. HRS attenuated CPB induced apoptosis in heart tissues. (A) Apoptosis-positive cells were determined via TUNEL assays and (B) stained with DAPI Reverse transcription-quantitative polymerase chain reaction and (C) western blot assays were performed to detect the expression levels of Bax (D) mRNA and (E) protein; caspase-3 (F) mRNA and (G) protein; and Bcl 2 (H) mRNA and (I) protein ${ }^{*} \mathrm{P}<0.05$ vs. sham group; ${ }^{*} \mathrm{P}<0.05$ vs. CPB group. CPB, cardiopulmonary bypass; HRS, hydrogen rich solution; Bax, apoptosis regulator Bax; Bcl-2, apoptosis regulator Bcl-2; TUNEL, terminal deoxynucleotidyl-transferase-mediated dUTP nick end labeling; DAPI, 4', 6-diamidino-2-phenylindole. 

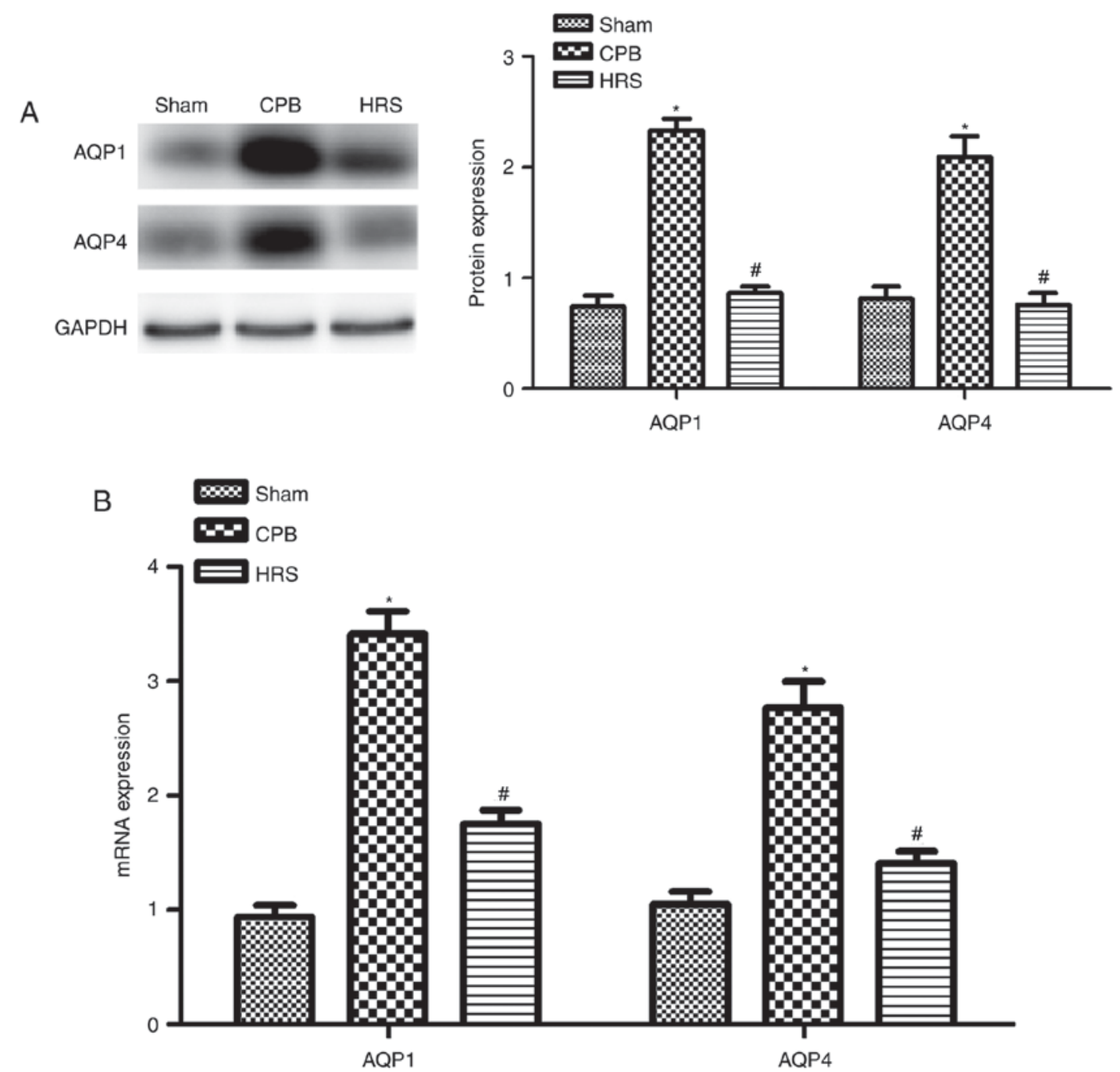

Figure 5. HRS suppressed AQP protein expression. (A) Western blot assays were performed to determine the protein expression levels of AQP1 and AQP4 proteins. (B) Reverse transcription-quantitative polymerase chain reaction was performed to determine the expression levels of AQP1 and AQP4 mRNA. Data among groups were compared using one-way analysis of variance. ${ }^{*} \mathrm{P}<0.05$ vs. sham group; ${ }^{\text {"}} \mathrm{P}<0.05$ vs. CPB group. CPB, cardiopulmonary bypass; HRS, hydrogen rich solution; $\mathrm{AQP}$, aquaporin.
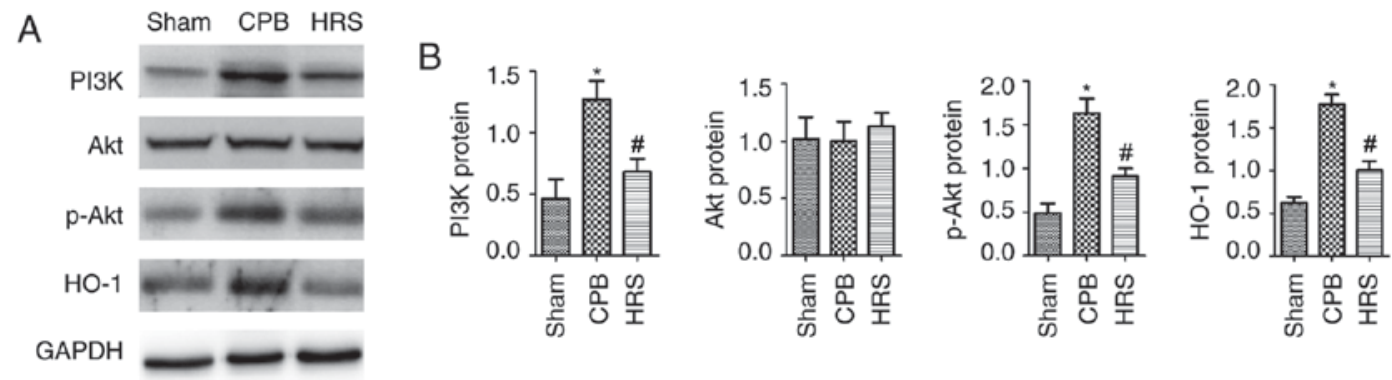

Figure 6. HRS suppressed apoptosis via the PI3K/Akt signaling pathway following CPB in rats. (A and B) Total protein was isolated, and the expression levels of PI3K, Akt, p-Akt and HO-1 proteins associated with the PI3K/Akt signaling pathway were determined by western blot assays. Data among multiple groups were compared using one-way analysis of variance. " $\mathrm{P}<0.05$ vs. sham group; ${ }^{~} \mathrm{P}<0.05$ vs. $\mathrm{CPB}$ group. $\mathrm{CPB}$, cardiopulmonary bypass; HRS, hydrogen rich solution; PI3K, phosphatidylinositol 3-kinase; Akt, protein kinase B; p-, phosphorylated; HO-1, heme oxygenase 1.

effect of HRS treatment was further investigated. The expression levels of Akt were similar to that of the CPB group. Additionally, HRS may promote the phosphorylation of Akt. In the LHRS group, the levels of p-Akt were significantly reduced compared with the HRS group (Fig. 8A and B). Furthermore, the expression of the downstream regulatory gene HO-1 was significantly reduced in the LHRS group compared with the HRS group (Fig. 8A and C). Therefore, the results suggest that HRS can suppress hypoxia/reoxygenation-induced heart injury via the PI3K/Akt signaling pathway. 
A

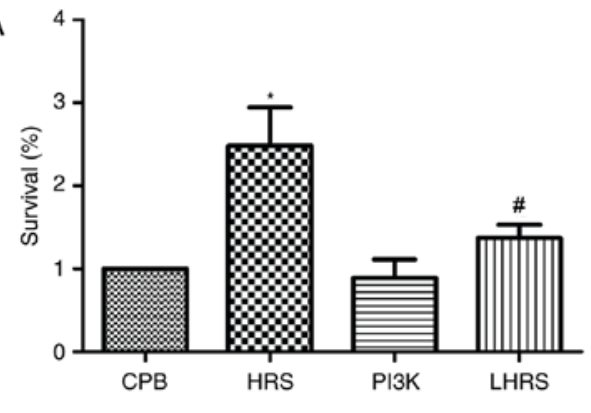

C

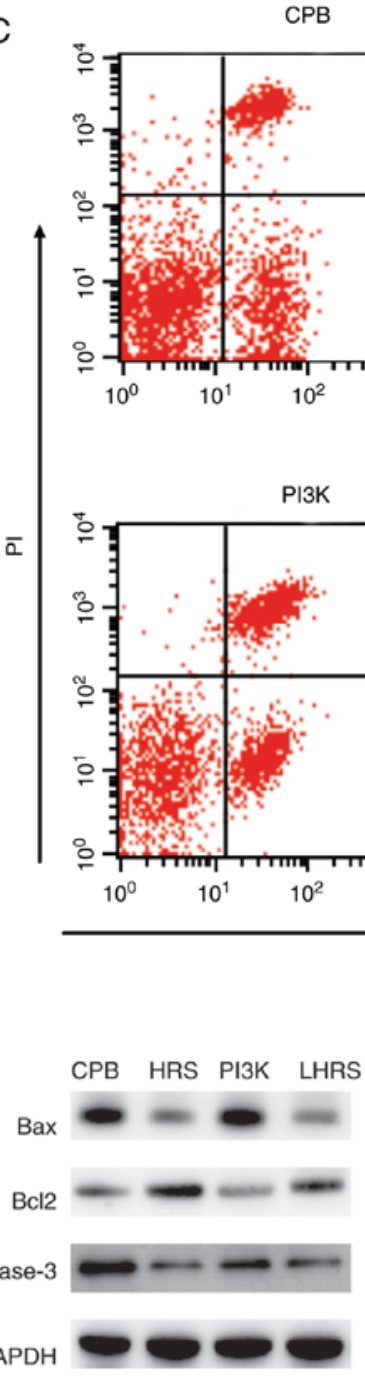

$\mathrm{E}$
$\mathrm{B}$
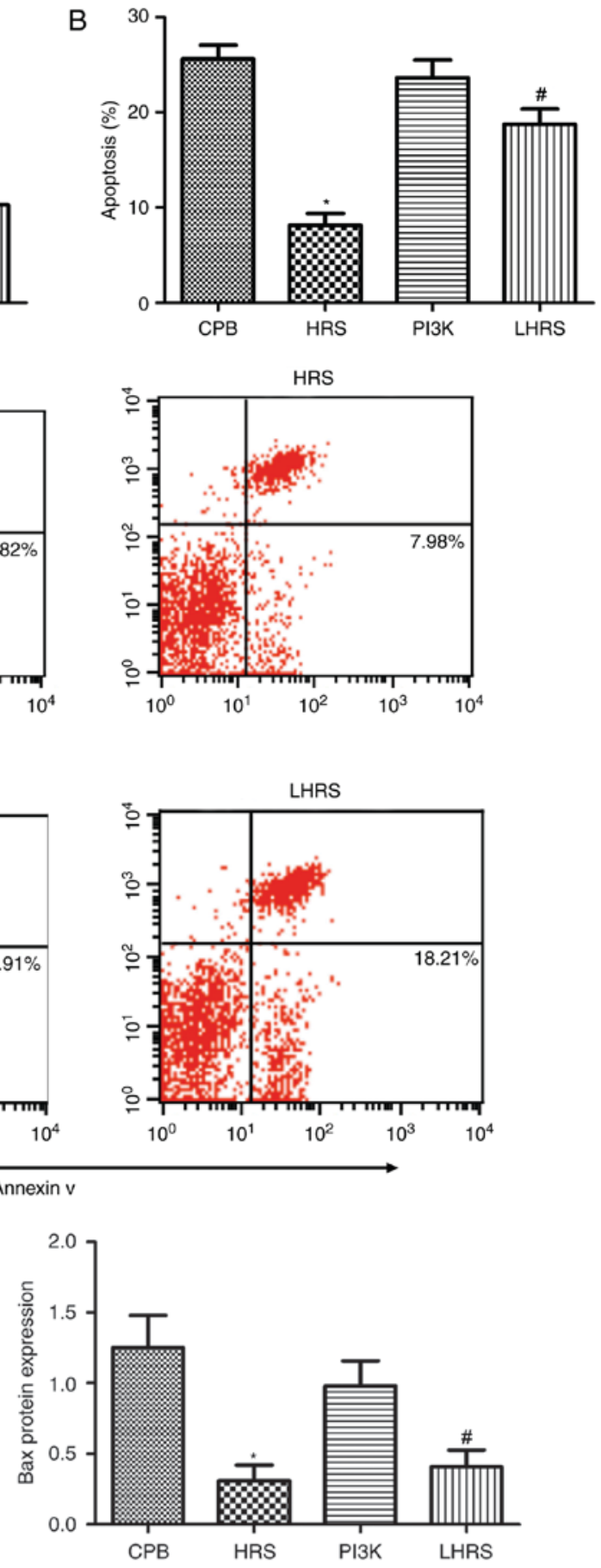

$\mathrm{F}$

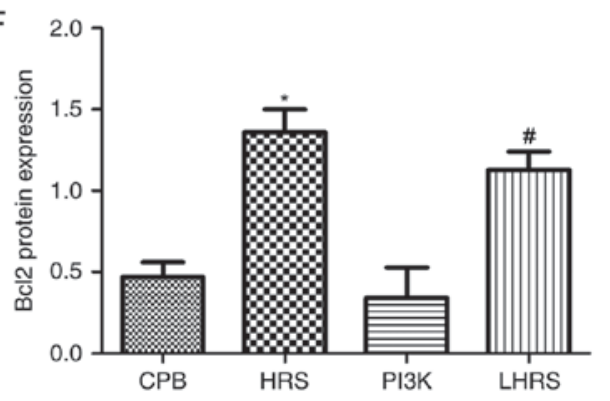

G

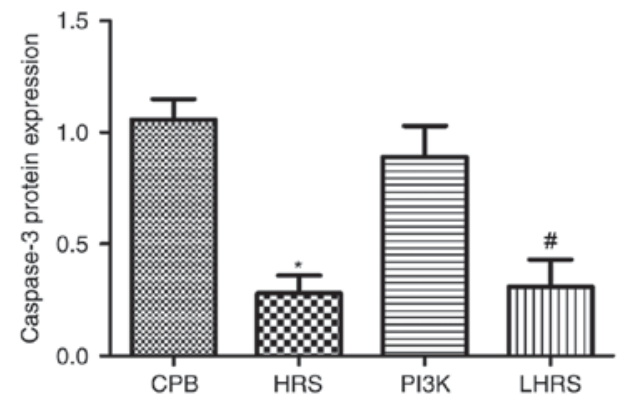

Figure 7. HRS enhanced the viability of myocardial cells and suppressed the apoptosis rate of myocardial cells in vitro. To further investigate the underlying therapeutic mechanism of HRS, H9C2 cells were used and HRS and LY294002 (PI3K signaling pathway inhibitor) treatments were applied. (A) An MTT assay was performed to determine cell viability. (B and C) Flow cytometry was performed to determine the cell apoptotic rate. (D) Western blot assays were performed. Expression levels of (E) Bax, (F) Bcl2 and (G) caspase-3 were quantified. "P<0.05 vs. CPB group; "P<0.05 vs. PI3K group. PI3K group, LY294002 + CPB; LHRS group, LY294002 + CPB + HRS; CPB, cardiopulmonary bypass; HRS, hydrogen rich solution; Bax, apoptosis regulator Bax; Bcl-2, apoptosis regulator Bcl-2. 

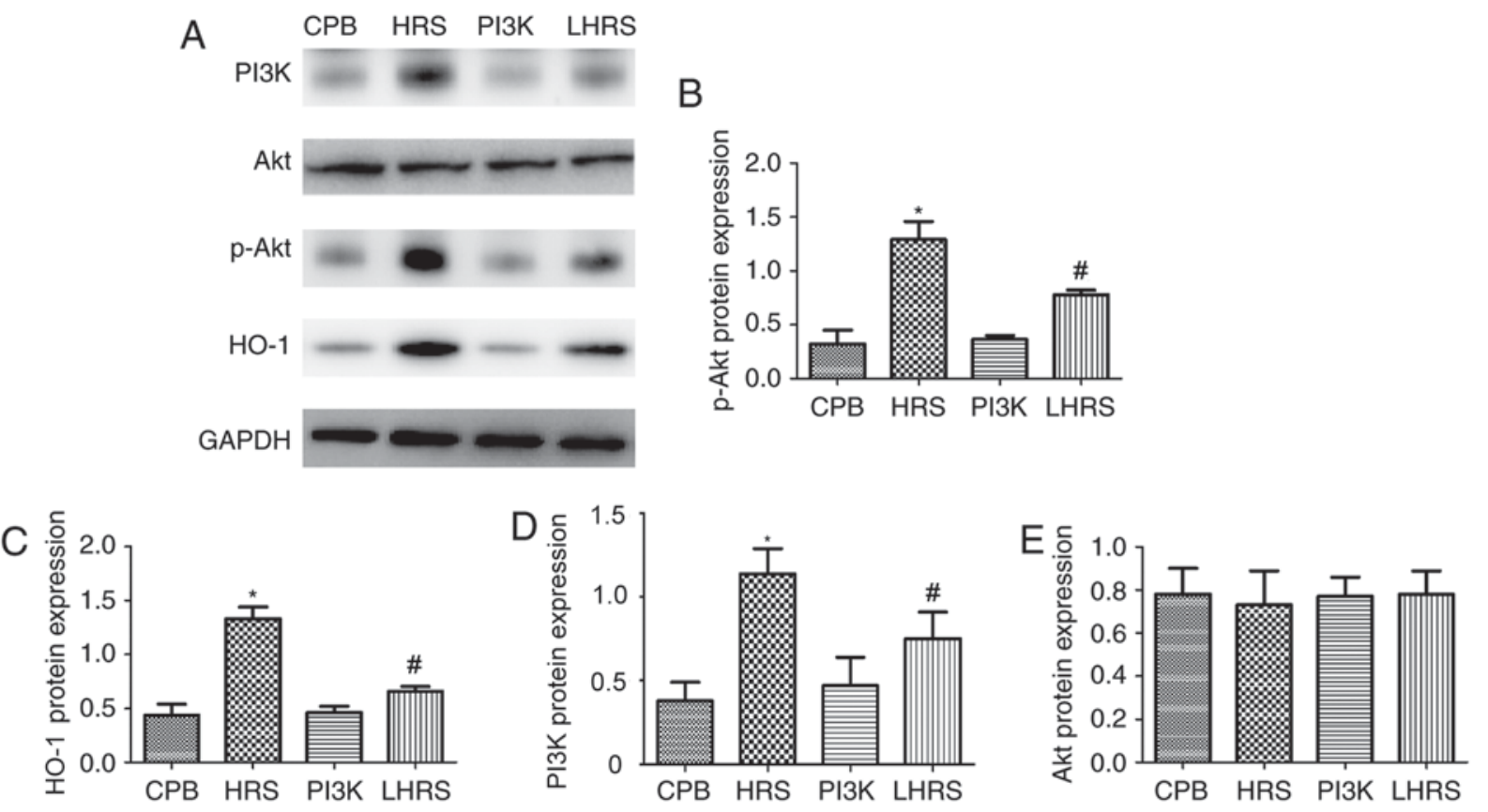

Figure 8. HRS suppressed myocardial cell apoptosis via the PI3K/Akt signaling pathway. (A) Western blot assays were performed. The levels of (B) p-Akt, (C) HO-1, (D) PI3K and (E) Akt were quantified. Data among multiple groups were compared using one-way analysis of variance. "P $<0.05$ vs. CPB group; ${ }^{\#}$ P $<0.05$ vs. PI3K group. PI3K group, LY294002 + CPB; LHRS group, LY294002 + CPB + HRS; CPB, cardiopulmonary bypass; HRS, hydrogen rich solution; PI3K, phosphatidylinositol 3-kinase; Akt, proein kinase B; p-, phosphrylated; HO-1, heme oxygenase 1.

\section{Discussion}

Myocardial injury is one of the common complications following $\mathrm{CPB}$, inducing a decrease in the diastolic and systolic functions of myocardium, arrhythmia, myocardial energy metabolism disturbance and microcirculation disorder (3). Myocardial injury may lead to heart failure, thus severely threatening the postoperative recovery of patients. The PI3K/Akt pathway has an important role in the oxidative stress and apoptosis of myocardial cells, and HRS inhibits myocardial injury via the PI3K/Akt pathway (22-24). The incidence of complications and mortality following open heart surgery with CPB is closely associated with the severity of myocardial injury during surgery. HRS has antioxidant stress, anti-apoptosis and anti-inflammation effects $(25,26)$. In the present study, a CPB model was established in vivo and in vitro to investigate the protective effect of HRS. The results of the present study revealed that HRS suppressed the expression of inflammatory factors in the rats, reduced the apoptotic rate of myocardial cells and inhibited the expression of aquaporins, through the PI3K/Akt signaling pathway.

Previous studies investigating ischemia-reperfusion injury during CPB have focused on the liver, kidney, intestine and brain, without cardiac arrest or cardiac resuscitation, and could not study heart and lung injury (27-30). In accordance with previous studies $(31,32)$, the present study made a number of modifications, and established rat models of CPB. Thus, the present study of myocardial protection with $\mathrm{CPB}$ is more in line with clinical practice.

Non-physiological blood circulation causes systemic inflammatory response syndrome during CPB (33). Furthermore, organ ischemia-reperfusion injury and surgical trauma are also important triggering factors of inflammatory response $(34,35)$. Various inflammatory factors are produced during $\mathrm{CPB}$, which may induce myocardial injury directly or indirectly (36). A previous study demonstrated that TNF- $\alpha$ levels increased following myocardial ischemia, and further increased following reperfusion, thereby aggravating myocardial injury (37). Another previous study revealed that suppression of TNF- $\alpha$ expression may attenuate myocardial injury (38). IL-6 is associated with reperfusion injury, and its expression is associated with the severity of left ventricular dysfunction and low cardiac output following thrombolytic therapy for myocardial infarction $(39,40)$. The results of the present study suggested that CPB significantly increased plasma TNF- $\alpha$ and IL- 6 levels. CPB induces systemic inflammation, and myocardial water content increased following the initiation of $\mathrm{CPB}$; thus, suggesting that CPR aggravated myocardial injury and affected cell membrane permeability. Furthermore, energy metabolism disorders may lead to cardiomyocyte edema.

Hydrogen is a therapeutic antioxidant, which can selectively suppress $\mathrm{OH}$-free radicals, and its effect is predominantly dependent on the antioxidant properties of hydrogen for the protection of organs from oxidative damage (4). The present study demonstrated that hydrogen may inhibit the release of cell adhesion molecules and inflammatory cytokines, as well as increase the level of anti-inflammatory factors. HRS is associated with metabolism, thereby regulating cell detoxification, cell hydration, and the immune system (41-43). Animal experiments and clinical trials have previously confirmed that HRS significantly inhibits heart, liver, lung and intestinal ischemia-reperfusion injury; as well as inhibiting inflammatory responses and apoptotic rates $(6,26,44)$. The present study suggested that HRS may inhibit CPB-induced myocardial injury by reducing LDH, CK-MB, IL- $1 \beta$, IL- 6 , TNF- $\alpha$, MDA 
and MPO levels; enhancing the release of SOD and decreasing the expression of proteins associated with apoptosis. These results suggest that HRS has a protective effect on $\mathrm{CPB}$-induced myocardial injury, and the mechanism underlying its protective effect is via anti-inflammatory and anti-apoptotic effects.

Cardiomyocyte edema is a predominant pathological change associated with myocardial injury (45). AQP-mediated transport of water molecules accounts for approximately $1 / 3$ of total water transport in cardiomyocytes (46). Under pathological conditions, the transmembrane transport of water molecules in cardiomyocytes predominantly depends upon the transport of AQPs (11). In the AQPs family, AQP-1 is most widely distributed among cardiomyocytes (47). Ding et al (9) demonstrated that AQP-1 expression is upregulated in cardiomyocytes and vascular endothelial cells in rabbit models of chronic myocardial ischemia. Myocardial ischemia and the severity of myocardial edema are consistent with AQP-1 expression (48), thus suggesting that a possible regulatory role of AQP-1 associated with myocardial edema induced by chronic myocardial ischemia. AQP-4 is another important $\mathrm{AQP}$ in the heart, and is predominantly distributed in intercalated discs, endothelial cells, sarcolemma and serosa in the heart $(49,50)$. When myocardial edema induced by myocardial infarction and water content in cardiomyocytes is increased, AQP-4 expression is upregulated in cardiomyocytes (51). AQP-4 mRNA and protein expression has been revealed to be associated with the area of myocardial infarction, thus suggesting that AQP-4 is involved in myocardial edema following myocardial infarction, and that the permeability of AQP-4 to water is greater than AQP-1 (52). In the present study, AQP-1 and -4 expression level were increased following the initiation of CPB, and markedly increased following CPB. HRS was revealed to suppress the expression of AQPs, thus suggesting that HRS can inhibit CPB induced myocardial edema.

In the present study of the myocardial IR model, the PI3K/Akt pathway has an important role in myocardial injury, such as inflammation and apoptosis. Soy isoflavone has a protective role in myocardial ischemia-reperfusion injury in ovariectomized rats via activation of the estrogen receptor in the $\mathrm{Pl3K} / \mathrm{Akt} / \mathrm{eNOS}$ signaling pathway (53). Therefore, the present study hypothesized that HRS may increase the activity of the PI3K/Akt pathway and induce the transcription and expression of the HO-1 gene. Firstly, the levels of p-Akt were investigated in the myocardium of each group, which is an important marker of PI3K/Akt activity. Consistent with previous studies HRS significantly enhanced the activity of PI3K/Akt $(54,55)$. Following this, a cell hypoxia-reoxygenation model, a simulated CPB model and a PI3K inhibitor model were established. The results demonstrated that LY294002 not only reversed the protective effect of HRS on myocardial injury following $\mathrm{CPB}$, but also suppressed the inhibition of AQP1, AQP4 and HO-1. These results demonstrated that the mechanism underlying the protective effect of HRS on myocardium and the inhibition of AQP protein expression may be associated with the activation of the PI3K/Akt pathway.

In conclusion, the present study revealed that the PI3K/Akt signaling pathway has an important role in the mechanism of CPB-induced myocardial injury. Furthermore, the results suggest that HRS may attenuate CPB-induced mitochondrial oxidative stress injury and apoptosis via the PI3K/Akt signaling pathway, thus leading to protective effects against myocardial injury.

\section{Acknowledgements}

Not applicable.

\section{Funding}

The present study was supported by the Natural Science Foundation of Liaoning Province (grant no. 2014020063) and the Natural Science Foundation of China (grant nos. 81471121 and 3120175).

\section{Availability of data and materials}

All data generated or analyzed during this study are included in this published article.

\section{Authors' contributions}

XL performed the reverse transcription-quantitative polymerase chain reaction and collected data. YG, YJ, GZ and $\mathrm{TZ}$ conducted the collection of samples. KY collected fresh samples. YJ and LP also contributed to acquisition of funding support. LP designed the study. DD conceived and designed the study, acquired data, interpreted the results and drafted the manuscript. All authors read and approved the final manuscript.

\section{Ethics approval and consent to participate}

The present study was approved by the China Medical University Laboratory Animal Welfare and Ethics Committee and adhered to the guidelines of The Institutional Animal Care and Use Committee; no. 2015048R.

\section{Consent for publication}

Not applicable.

\section{Competing interest}

The authors declare that they have no competing interests.

\section{References}

1. Suleiman MS, Zacharowski K and Angelini GD: Inflammatory response and cardioprotection during open-heart surgery: The importance of anaesthetics. Br J Pharmacol 153: 21-33, 2008.

2. Steuer J, Granath F, de Faire U, Ekbom A and Stahle E: Increased risk of heart failure as a consequence of perioperative myocardial injury after coronary artery bypass grafting. Heart 91: 754-758, 2005.

3. De Hert S and Moerman A: Myocardial injury and protection related to cardiopulmonary bypass. Best Pract Res Clin Anaesthesiol 29: 137-149, 2015.

4. Ohsawa I, Ishikawa M, Takahashi K, Watanabe M, Nishimaki K, Yamagata K, Katsura K, Katayama Y, Asoh S and Ohta S: Hydrogen acts as a therapeutic antioxidant by selectively reducing cytotoxic oxygen radicals. Nat Med 13: 688-694, 2007.

5. Qian L, Li B, Cai J and Gao F: The hypothesis of an effective safe and novel radioprotective agent: Hydrogen-rich solution. West Indian Med J 59: 122-124, 2010. 
6. Noda K, Shigemura N, Tanaka Y, Kawamura T, Hyun Lim S, Kokubo K, Billiar TR, Bermudez CA, Kobayashi $\mathrm{H}$ and Nakao A: A novel method of preserving cardiac grafts using a hydrogen-rich water bath. J Heart Lung Transplant 32: 241-250, 2013.

7. Nagaraju GP, Basha R, Rajitha B, Alese OB, Alam A, Pattnaik S and El-Rayes B: Aquaporins: Their role in gastrointestinal malignancies. Cancer Lett 373: 12-18, 2016.

8. Jonker S, Davis LE, van der Bilt JD, Hadder B, Hohimer AR, Giraud GD and Thornburg KL: Anaemia stimulates aquaporin 1 expression in the fetal sheep heart. Exp Physiol 88: 691-698, 2003.

9. Ding FB, Yan YM, Huang JB, Mei J, Zhu JQ and Liu H: The involvement of AQP1 in heart oedema induced by global myocardial ischemia. Cell Biochem Funct 31: 60-64, 2013.

10. Butler TL, Au CG, Yang B, Egan JR, Tan YM, Hardeman EC, North KN, Verkman AS and Winlaw DS: Cardiac aquaporin expression in humans, rats, and mice. Am J Physiol Heart Circ Physiol 291: H705-H713, 2006.

11. Rutkovskiy A, Stenslokken KO, Mariero LH, Skrbic B Amiry-Moghaddam M, Hillestad V, Valen G, Perreault MC, Ottersen OP, Gullestad L, et al: Aquaporin-4 in the heart: Expression, regulation and functional role in ischemia. Basic Res Cardiol 107: 280, 2012

12. Chaudhuri S, Singh MK, Bhattacharya D, Datta A, Hazra I, Mondal S, Faruk Sk Md O, Ronsard L, Ghosh TK and Chaudhuri S: T11TS immunotherapy repairs PI3K-AKT signaling in T-cells: Clues toward enhanced T-cell survival in rat glioma model. J Cell Physiol 233: 759-770, 2018.

13. Zhu X, Huang H, Zhang J, Liu H, Ao R, Xiao M and Wu Y: The anticancer effects of Cucurbitacin I inhibited cell growth of human non-small cell lung cancer through PI3K/AKT/p70S6K pathway. Mol Med Rep 17: 2750-2756, 2018.

14. Zhang B, Liu Y, Li Y, Zhe X, Zhang S and Zhang L: Neuroglobin promotes the proliferation and suppresses the apoptosis of glioma cells by activating the PI3K/AKT pathway. Mol Med Rep 17: 2757-2763, 2018.

15. Wu MP, Zhang YS, Zhou QM, Xiong J, Dong YR and Yan C: Higenamine protects ischemia/reperfusion induced cardiac injury and myocyte apoptosis through activation of $\beta 2-\mathrm{AR} / \mathrm{PI} 3 \mathrm{~K} / \mathrm{AKT}$ signaling pathway. Pharmacol Res 104 $115-123,2016$.

16. Hu S, Zhang Y, Zhang M, Guo Y, Yang P, Zhang S, Simsekyilmaz S, Xu JF, Li J, Xiang X, et al: Aloperine protects mice against ischemia reperfusion (IR)-induced renal injury by regulating $\mathrm{PI} 3 \mathrm{~K} / \mathrm{AKT} / \mathrm{mTOR}$ signaling and AP-1 activity. Mol Med: Nov 3, 2015 (Epub ahead of print).

17. Yang C, Cao Y, Zhang Y, Li L, Xu M, Long Y, Rong R and Zhu T: Cyclic helix B peptide inhibits ischemia reperfusion-induced renal fibrosis via the PI3K/Akt/FoxO3a pathway. J Transl Med 13: 355, 2015.

18. Sun Y, Jiang C, Jiang J and Qiu L: Dexmedetomidine protects mice against myocardium ischaemic/reperfusion injury by activating an AMPK/PI3K/Akt/eNOS pathway. Clin Exp Pharmacol Physiol 44: 946-953, 2017.

19. Zhang J, Wu Q, Song S, Wan Y, Zhang R, Tai M and Liu C: Effect of hydrogen-rich water on acute peritonitis of rat models Int Immunopharmacol 21: 94-101, 2014

20. Stark RA, Nahrwold ML and Cohen PJ: Blind oral tracheal intubation of rats. J Appl Physiol Respir Environ Exerc Physiol 51: 1355-1356, 1981.

21. Livak KJ and Schmittgen TD: Analysis of relative gene expression data using real-time quantitative PCR and the 2(-Delta Delta C(T)) method. Methods 25: 402-408, 2001.

22. Xu F, Yu H, Liu J and Cheng L: $\alpha B$-crystallin regulates oxidative stress-induced apoptosis in cardiac $\mathrm{H} 9 \mathrm{c} 2$ cells via the PI3K/AKT pathway. Mol Biol Rep 40: 2517-2526, 2013.

23. Su D, Zhou Y,Hu S, Guan L, Shi C, Wang Q, Chen Y,Lu C, Li Q and Ma X: Role of GAB1/PI3K/AKT signaling high glucose-induced cardiomyocyte apoptosis. Biomed Pharmacother 93: 1197-1204, 2017.

24. Chen K, Wang N, Diao Y, Dong W, Sun Y, Liu L and Wu X: Hydrogen-rich saline attenuates brain injury induced by cardiopulmonary bypass and inhibits microvascular endothelial cel apoptosis via the PI3K/Akt/GSK3 $\beta$ signaling pathway in rats. Cell Physiol Biochem 43: 1634-1647, 2017.

25. Li J, Hong Z, Liu H, Zhou J, Cui L, Yuan S, Chu X and Yu P: Hydrogen-rich saline promotes the recovery of renal function after ischemia/reperfusion injury in rats via anti-apoptosis and anti-inflammation. Front Pharmacol 7: 106, 2016.
26. Shigeta T, Sakamoto S, Li XK, Cai S, Liu C, Kurokawa R, Nakazawa A, Kasahara M and Uemoto S: Luminal injection of hydrogen-rich solution attenuates intestinal ischemia-reperfusion injury in rats. Transplantation 99: 500-507, 2015.

27. Li T, Luo N, Du L, Zhou J, Zhang J, Gong L and Jiang N: Tumor necrosis factor- $\alpha$ plays an initiating role in extracorporeal circulation-induced acute lung injury. Lung 191: 207-214, 2013.

28. Kim J, Yin T, Shinozaki K, Lampe JW and Becker LB DHA-supplemented diet increases the survival of rats following asphyxia-induced cardiac arrest and cardiopulmonary bypass resuscitation. Sci Rep 6: 36545, 2016.

29. Cai DS, Jin BB, Pei L and Jin Z: Protective effects of penehyclidine hydrochloride on liver injury in a rat cardiopulmonary bypass model. Eur J Anaesthesiol 27: 824-828, 2010.

30. Aregger F, Pilop C, Uehlinger DE, Brunisholz R, Carrel TP Frey FJ and Frey BM: Urinary proteomics before and after extracorporeal circulation in patients with and without acute kidney injury. J Thorac Cardiovasc Surg 139: 692-700, 2010.

31. Zhou J, Zhou N, Wu XN, Cao HJ, Sun YJ, Zhang TZ, Chen KY and Yu DM: Role of the Tolllike receptor 3 signaling pathway in the neuroprotective effect of sevoflurane pre-conditioning during cardiopulmonary bypass in rats. Mol Med Rep 12: 7859-7868, 2015.

32. Peterss S, Guenther S, Kellermann K, Jungwirth B, Lichtinghagen R, Haverich A, Hagl C and Khaladj N: An experimental model of myocardial infarction and controlled reperfusion using a miniaturized cardiopulmonary bypass in rats. Interact Cardiovasc Thorac Surg 19: 561-566, 2014

33. Baehner T, Boehm O, Probst C, Poetzsch B, Hoeft A, Baumgarten $\mathrm{G}$ and Knuefermann P: Cardiopulmonary bypass in cardiac surgery. Anaesthesist 61: 846-856, 2012.

34. Prondzinsky R, Knupfer A, Loppnow H, Redling F, Lehmann DW, Stabenow I, Witthaut R, Unverzagt S, Radke J, Zerkowski HR and Werdan K: Surgical trauma affects the proinflammatory status after cardiac surgery to a higher degree than cardiopulmonary bypass. J Thorac Cardiovasc Surg 129: 760-766, 2005.

35. Balogh AL, Petak F, Fodor GH, Sudy R and Babik B: Sevoflurane relieves lung function deterioration after cardiopulmonary bypass. J Cardiothorac Vasc Anesth 31: 2017-2026, 2017.

36. Tavener SA, Long EM, Robbins SM, McRae KM, Van Remmen H and Kubes P: Immune cell Toll-like receptor 4 is required for cardiac myocyte impairment during endotoxemia. Circ Res 95: 700-707, 2004

37. Liu WB, Han XH, Guo YY, Zhang DM, Tang FJ, Zhao L, Ji LL and Guo FM: Effects of tumor necrosis factor and E-selectin on coronary artery flow. Eur Rev Med Pharmacol Sci 21: 1843-1849, 2017.

38. Sadeghzadeh J, Vakili A, Bandegi AR, Sameni HR, Zahedi Khorasani $\mathrm{M}$ and Darabian M: Lavandula reduces heart injury via attenuating tumor necrosis factor-alpha and oxidative stress in a rat model of infarct-like myocardial injury. Cell J 19: 84-93, 2017.

39. Sonnino C, Christopher S, Oddi C, Toldo S, Falcao RA, Melchior RD, Mueller GH, Abouzaki NA, Varma A, Gambill ML, et al: Leukocyte activity in patients with ST-segment elevation acute myocardial infarction treated with anakinra. Mol Med 20: 486-489, 2014.

40. Ikonomidis I, Athanassopoulos G, Lekakis J, Venetsanou K, Marinou M, Stamatelopoulos K, Cokkinos DV and Nihoyannopoulos P: Myocardial ischemia induces interleukin- 6 and tissue factor production in patients with coronary artery disease: A dobutamine stress echocardiography study. Circulation 112: 3272-3279, 2005.

41. Cui W, Gao C, Fang P, Lin G and Shen W: Alleviation of cadmium toxicity in Medicago sativa by hydrogen-rich water. J Hazard Mater 260: 715-724, 2013.

42. Aoki K, Nakao A, Adachi T, Matsui Y and Miyakawa S: Pilot study: Effects of drinking hydrogen-rich water on muscle fatigue caused by acute exercise in elite athletes. Med Gas Res 2: 12, 2012.

43. Zhao S, Yang Y, Liu W, Xuan Z, Wu S, Yu S, Mei K, Huang Y, Zhang P, Cai J, et al: Protective effect of hydrogen-rich saline against radiation-induced immune dysfunction. J Cell Mol Med 18: 938-946, 2014

44. Takahashi M, Chen-Yoshikawa TF, Saito M, Tanaka S, Miyamoto E, Ohata K, Kondo T, Motoyama H, Hijiya K, Aoyama $\mathrm{A}$ and Date $\mathrm{H}$ : Immersing lungs in hydrogen-rich saline attenuates lung ischaemia-reperfusion injury. Eur J Cardiothorac Surg 51: 442-448, 2017

45. Schulz-Menger J: Myocardial edema in acute ischemic injury. JACC Cardiovasc Imaging 4: 279-281, 2011. 
46. Rutkovskiy A, Valen G and Vaage J: Cardiac aquaporins. Basic Res Cardiol 108: 393, 2013.

47. Netti VA, Vatrella MC, Chamorro MF, Rosón MI, Zotta E Fellet AL and Balaszczuk AM: Comparison of cardiovascular aquaporin-1 changes during water restriction between 25 - and 50-day-old rats. Eur J Nutr 53: 287-295, 2014.

48. Rutkovskiy A, Bliksoen M,Hillestad V, Amin M, Czibik G, Valen G, Vaage J, Amiry-Moghaddam M and Stensløkken KO: Aquaporin-1 in cardiac endothelial cells is downregulated in ischemia, hypoxia and cardioplegia. J Mol Cell Cardiol 56: 22-33, 2013.

49. Wu Y, Pan CY, Guo CZ, Dong ZJ, Wu Q, Dong HM and Zhang W: Expression of aquaporin 1 and 4 in rats with acute hypoxic lung injury and its significance. Genet Mol Res 14: 12756-12764, 2015.

50. Tie L, Wang D, Shi Y and Li X: Aquaporins in cardiovascular system. Adv Exp Med Biol 969: 105-113, 2017.

51. Zhang HZ, Kim MH, Lim JH and Bae HR: Time-dependent expression patterns of cardiac aquaporins following myocardial infarction. J Korean Med Sci 28: 402-408, 2013.

52. Warth A, Eckle T, Kohler D, Faigle M, Zug S, Klingel K Eltzschig HK and Wolburg H: Upregulation of the water channel aquaporin-4 as a potential cause of postischemic cell swelling in a murine model of myocardial infarction. Cardiology 107: 402-410, 2007.
53. Tang Y, Li S, Zhang P, Zhu J, Meng G, Xie L, Yu Y, Ji Y and Han Y: Soy isoflavone protects myocardial ischemia/reperfusion injury through increasing endothelial nitric oxide synthase and decreasing oxidative stress in ovariectomized rats. Oxid Med Cell Longev 2016: 5057405, 2016.

54. Hong Y, Shao A, Wang J, Chen S, Wu H, McBride DW, Wu Q, Sun $X$ and Zhang J: Neuroprotective effect of hydrogen-rich saline against neurologic damage and apoptosis in early brain injury following subarachnoid hemorrhage: Possible role of the Akt/GSK3 $\beta$ signaling pathway. PLoS One 9: e96212, 2014.

55. Wu D, Liang M, Dang H, Fang F, Xu F and Liu C: Hydrogen protects against hyperoxia-induced apoptosis in type II alveolar epithelial cells via activation of PI3K/Akt/Foxo3a signaling pathway. Biochem Biophys Res Commun 495: 1620-1627, 2018.

This work is licensed under a Creative Commons Attribution-NonCommercial-NoDerivatives 4.0 International (CC BY-NC-ND 4.0) License. 